\title{
New insights into the delayed initiation of a debris flow in southwest China
}

\section{Taixin Peng}

Institute of Mountain Hazards and Environment Chinese Academy of Sciences

N. Sh. Chen ( $\square$ chennsh@imde.ac.cn )

Institute of Mountain Hazards and Environment https://orcid.org/0000-0002-6135-0739

\section{Guisheng Hu}

Institute of Mountain Hazards and Environment Chinese Academy of Sciences

\section{Shufeng Tian}

Institute of Mountain Hazards and Environment Chinese Academy of Sciences

\section{Zheng Han}

Central South University

Enlong Liu

Sichuan University

\section{Research Article}

Keywords: delayed debris flow, hollow deposits, landslide initiation, fluid-solid coupling

Posted Date: February 23rd, 2021

DOI: https://doi.org/10.21203/rs.3.rs-221141/v1

License: (c) (i) This work is licensed under a Creative Commons Attribution 4.0 International License.

Read Full License 


\section{New insights into the delayed initiation of a debris flow in}

\section{2 southwest China}

3 Taixin Peng ${ }^{1,2}$, Ningsheng Chen ${ }^{1,3, *}$, Guisheng $\mathrm{Hu}^{1,3}$, Shufeng Tian ${ }^{1,2}$, Zheng $\mathrm{Han}^{4}$, Enlong

$4 \mathrm{Liu}^{5}$

5 Corresponding author. Ningsheng Chen (chennsh@imde.ac.cn.)

61 Key Lab of Mountain Hazards and Surface Process, Institute of Mountain Hazards and

7 Environment (IMHE), Chinese Academy of Sciences, Chengdu 610041, China.

82 University of Chinese Academy of Sciences, Beijing 100049, China.

93 Academy of Plateau Science and Sustainability, Xining 810016, P.R.China.

104 School of Civil Engineering, Central South University, Changsha, 410075, China.

115 State Key Laboratory of Hydraulics and Mountain River Engineering, College of Water

12 Resources and Hydropower, Sichuan University, Chengdu 610065, China.

13 Abstract. ${ }^{1}$ On 6 July 2020, 3 h 40 min after rainfall stopped, a delayed debris-flow disaster

14 occurred due to colluvium deposits in a hollow region (CDH) in the Chenghuangmiao gully,

15 Sichuan Province, China, which resulted in 4 deaths and 27 injuries. This study explores the

\footnotetext{
${ }^{1}$ Abbreviations

$\mathrm{CDH}$ : colluvium deposits in a hollow region; SCS: US Soil Conservation Service
} 
16 initiation process of the delayed debris flow and the cause for the delay. Field investigations,

17 catchment geometry interpretation, laboratory tests, theoretical calculations, and fluid-solid

18 coupling numerical simulation were performed to obtain landslide parameters and understand

19 the mechanisms of the event. Results show: (1) The event was a giant low-frequency viscous

20 debris flow. (2) Its initiation was caused by the delayed landslide process under the influence

21 of back-end confluence. (3) The debris-flow discharge in the main gully increased over 19.5

22 min. (4) The seepage process inside the $\mathrm{CDH}$ continued for $3 \mathrm{~h} 20$ min after the rainfall

23 stopped before its pore pressure and reduction in strength was sufficient to initiate the debris

24 flow. This research provides new insights on delayed debris-flow disasters; it is a reference

25 for improving disaster management systems, especially monitoring and early warning

26 systems, thereby avoiding future casualties.

27 Keywords: delayed debris flow; hollow deposits; landslide initiation; fluid-solid coupling

\section{Introduction}

29 Debris flows are triggered by high-intensity and short-duration, or low-intensity and long-

30 duration rainfall (Iverson 1997; Iverson et al. 1997). When rainfall intensity and duration

31 reach critical levels, debris flow occurs (Baum and Godt 2010; Cannon et al. 2011; Cannon et

32 al. 2008; Guzzetti et al. 2008). Therefore, China's Sichuan Province has established many

33 rainfall stations to monitor likely occurrences of debris flow in vulnerable areas and warn

34 people about them. During 2019-2020, warnings for 14 debris flows were successfully issued, 
35 preventing 4932 casualties. However, this early warning mechanism is not perfect as delays

36 make the warnings ineffective. The Chenghuangmiao Gully experienced heavy rainfall in

37 Aba, Sichuan on 5 July, 2020. People were evacuated when the alarm sounded, and they

38 returned when the rain stopped; however, the debris-flow disaster initiated by the colluvium

39 deposits in a hollow region (CDH) occurred 3 h 40 min after the rainfall stopped, causing 4

40 deaths. Accordingly, the following questions must be addressed: How was this delayed debris

41 flow initiated? What caused the delay?

42 Delays in the occurrence of landslides after rainfall is a common phenomenon. Because they

43 may take a long time to develop. The development of landslides has three stages: initial,

44 secondary, and accelerated deformation. Statistical data on 20 large-scale landslides show

45 that the three stages together take 21 to 2135 days (Deng et al. 2000; Huang et al. 2012; Lee

46 et al. 2014; Li et al. 2016; Qi et al. 2006; Qiang et al. 2008). As the delay in the development

47 of a landslide occurs, delay in the resultant debris flow is possible. Analyses through

48 numerous cases studies and experiments have explained the initiation mechanism of debris

49 flow triggered by landslides. High pore pressure causes softening or liquefaction of the soil to

50 initiate debris flow; however, researchers have suggested that the processes involved in this

51 type of debris flow must be studied further (Crosta and Dal Negro 2003; Feng et al. 2005;

52 Iverson and Denlinger 2001; Iverson and Vallance 2001). The debris-flow disaster initiated

53 by the $\mathrm{CDH}$ landslide resulted from processes such as rainfall generation and confluence of 
54 streams, landslide, and debris flow (Chen et al. 2007; Zhang et al. 2019). As these three

55 processes occur over various durations, they must be studied individually. The following

56 approaches are relevant:

57 1) Rainfall generation and confluence: The US Soil Conservation Service (SCS) model and 58 the rational formula model are universally recognised and are also used in China. These

59 methods involve calculating the total surface runoff, the runoff generation time, and the peak

60 flow of confluence by combining rational formulas with regional experience coefficients

61 (Alfieri et al. 2008; Hua et al. 2003; Mishra and Singh 2003; Yue et al. 2012). 2) The CDH

62 landslide: Seepage and deformation occurred in the CDH simultaneously under the influence

63 of back-end confluence; their interaction (fluid-solid coupling) can be simulated using the

64 finite-difference software (Kim et al. 2018; Singh et al. 2008; Zhou et al. 2019). 3) Debris

65 flow: Calculation of velocity and discharge of debris flow based on cross-section 66 investigation; this method is widely used for preliminary evaluation of debris flow and

67 engineering treatment (Chen et al. 2015).

68 In general, from the onset of rainfall to the occurrence of debris flow, there were mature

69 studies on back end confluence, seepage and deformation of the landslide, and debris flow

70 respectively. However, the disaster's physical process was not connected in series on the

71 timeline as real happened. The phenomenon of debris flow delay is mentioned in literature

72 but has not been researched adequately. In this study, we use the SCS model and the rational 
73 formula to calculate the back-end confluence of the $\mathrm{CDH}$; we then use a numerical method to

74 simulate the debris flow initiated by the $\mathrm{CDH}$ landslide in the conditions of the back-end

75 confluence. Through field investigation, catchment geometry interpretation, and laboratory

76 tests the debris flow was characterized. Consequently, we identified the process of debris

77 flow initiation and the reasons for the delay in its onset.

\section{$78 \quad 2$ Study area}

\subsection{Overview of geography, geology, and watershed of the catchment}

80 The study area is located at the junction of Xiaojin County and Danba County in Sichuan

81 Province, China, at a valley on the southeast edge of the Qinghai-Tibet Plateau. The region

82 comprises middle mountain landforms that exhibit rapid structural uplift, deep river cutting,

83 and intense erosion and weathering (Fig. 1a). The study area is situated in the western wing

84 of the Xiaojin Arc structure, which comprises two anticlines that sandwich a syncline; the

85 three folds are aligned along the N-SW direction. The Chenghuangmiao Gully flows between

86 the cores of the two anticlines (Fig. 1c). The lithology of the study area comprises slates,

87 quartzites, and interbedded sandstones (Fig. 1c).

88 The watershed where the debris flow erupted belongs to a branch of the Xiaojinchuan River

89 at the Chenghuangmiao Gully. The watershed area is $6.1 \mathrm{~km}^{2}$, altitude is between $2168 \mathrm{~m}$ and

$904252 \mathrm{~m}$, and relief of the basin is $2084 \mathrm{~m}$. The Xiaojinchuan River and the Provincial

91 Highway S303 pass through the mouth of the gully. Based on the longitudinal gradient and 
92 source distribution of the Chenghuangmiao Gully, the watershed is divided into the

93 confluence area (Shimizu area) at the back end of the $\mathrm{CDH}$, initiation and transition area, and

94 accumulation area. The Shimizu area is located in the upper reaches of the Chenghuangmiao

95 Gully above the altitude of $4060 \mathrm{~m}$, with an area of $0.123 \mathrm{~km}^{2}$ and a slope of $26-38^{\circ}$. The

96 vegetation in the area is developed and the humus layer and colluvium deposits are $0.9-2.3 \mathrm{~m}$

97 thick. The concave terrain at the junction of the two watersheds provides favourable

98 conditions for runoff confluence at the back end of the $\mathrm{CDH}$. The altitudes of the initiation

99 and transition areas are between $4060 \mathrm{~m}$ and $2250 \mathrm{~m}$, length is approximately $4.95 \mathrm{~km}$, and

100 area is approximately $5.930 \mathrm{~km}^{2}$. Abundant loose materials and steep gradient channels

101 provide favourable conditions for the initiation and transition of debris flows. The

102 accumulation area is located from the mouth of the Chenghuangmiao Gully (2250 $\mathrm{m}$ in

103 elevation) to the confluence point with the Xiaojinchuan river (2168 $\mathrm{m}$ in elevation) and the

104 area is approximately $0.047 \mathrm{~km}^{2}$. The relatively low slope provides good topographical

105 conditions for the accumulation of debris (Fig. 1a and b). 


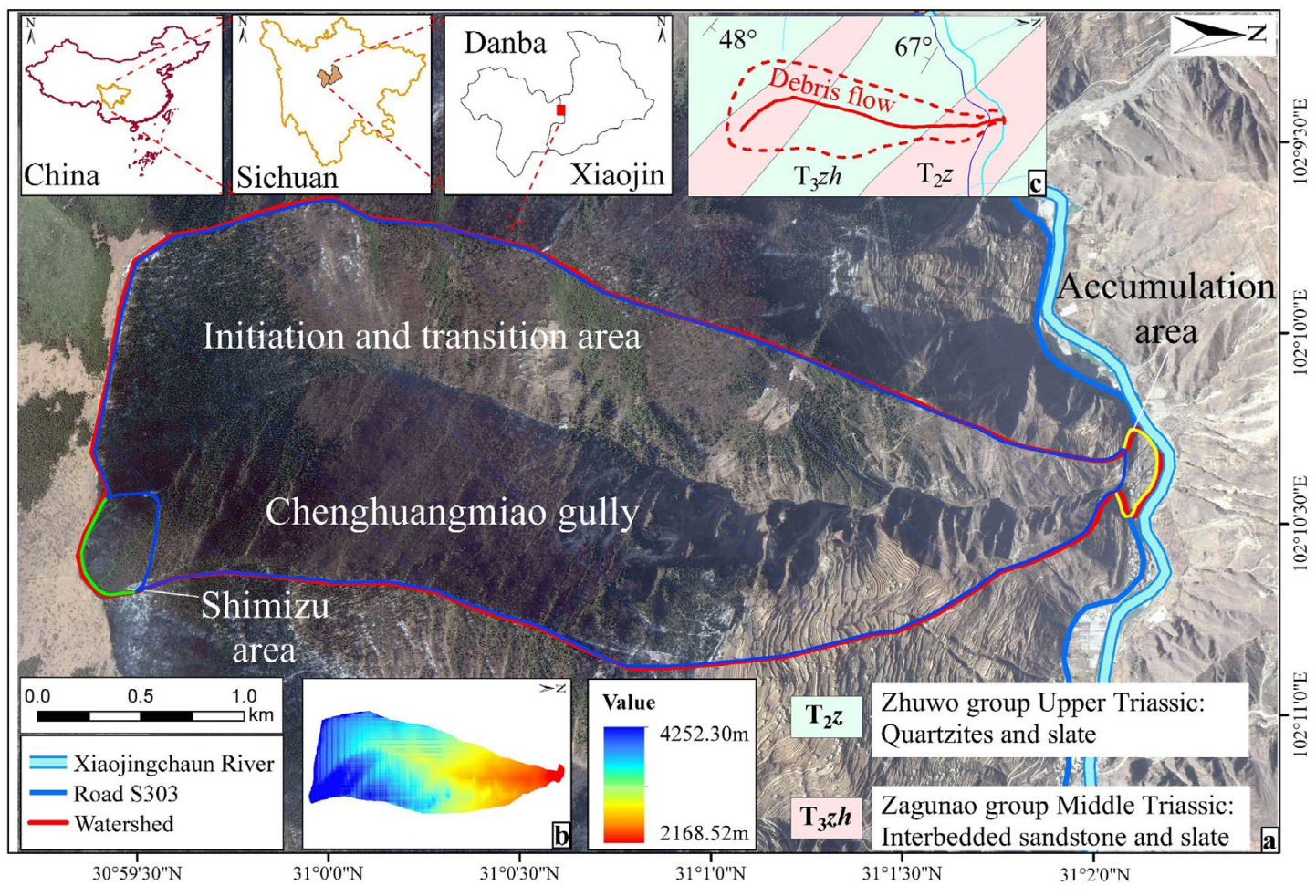

107 Fig. 1. Chenghuangmiao Gully: (a) watershed; (b) altitude; (c) geological map.

\section{$108 \quad 2.2$ Weather overview}

109 The study area experienced sparse rainfall in spring and heavy rainfall in June; intermittent

110 heavy rainfall occurred before the debris flow event. According to statistics, the maximum

111 monthly precipitation in the study area since 1952 was $233.9 \mathrm{~mm}$, and the precipitation in

112 June $2020(222.6 \mathrm{~mm})$, before the occurrence of the debris flow, was close to the historical

113 peak (Fig. 2a and b). The maximum daily rainfall of $30 \mathrm{~mm} / \mathrm{d}$ occurred on the day before the

114 occurrence of the debris flow (5 July 2020); this value was close to the historical maximum

115 daily rainfall of $37.8 \mathrm{~mm} / \mathrm{d}$ (Fig. 2c). The maximum hourly rainfall was $7.6 \mathrm{~mm} / \mathrm{h}$ from 21:00 
116 to $22: 00 \mathrm{~h}$ on 5 July 2020 (Fig. 2d). The data show that rainfall occurred throughout the area

117 during 01:00-08:00 $\mathrm{h}$ and 19:00-24:00 $\mathrm{h}$ on 5 July 2020. The effective rainfall was

118 approximately $17.0 \mathrm{~mm}$ before the disaster (Fig. 2e).
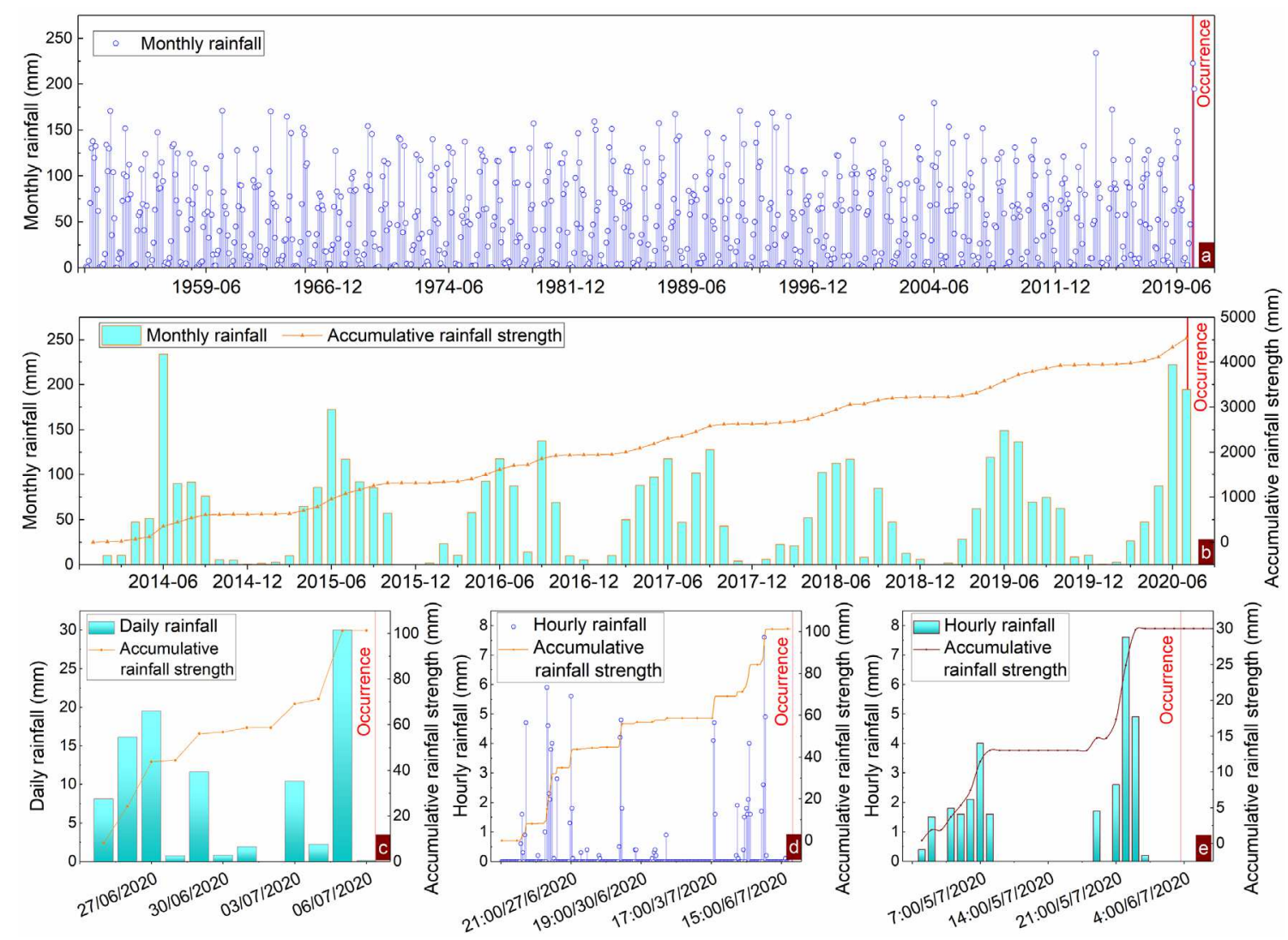

120 Fig. 2. Rainfall trends in the study area: (a) Monthly rainfall from 1952; (b) Monthly rainfall

121 from 2014 to 2020; (c) Daily rainfall in the 12 days before the occurrence of debris flow; (d)

122 Hourly rainfall in the 12 days before the occurrence; (f) Hourly rainfall $30 \mathrm{~h}$ before the

123 occurrence. 


\section{Methodology}

125 Field investigations, catchment geometry interpretation, and laboratory tests were conducted

126 to obtain data on deposits and terrain parameters for the characterisation of the gully after the

127 debris-flow disaster. Theoretical calculations and numerical simulation methods were

128 performed to obtain the parameters regarding rainfall, runoff, $\mathrm{CDH}$ landslide at the debris-

129 flow source, and debris flow (Fig. 3).

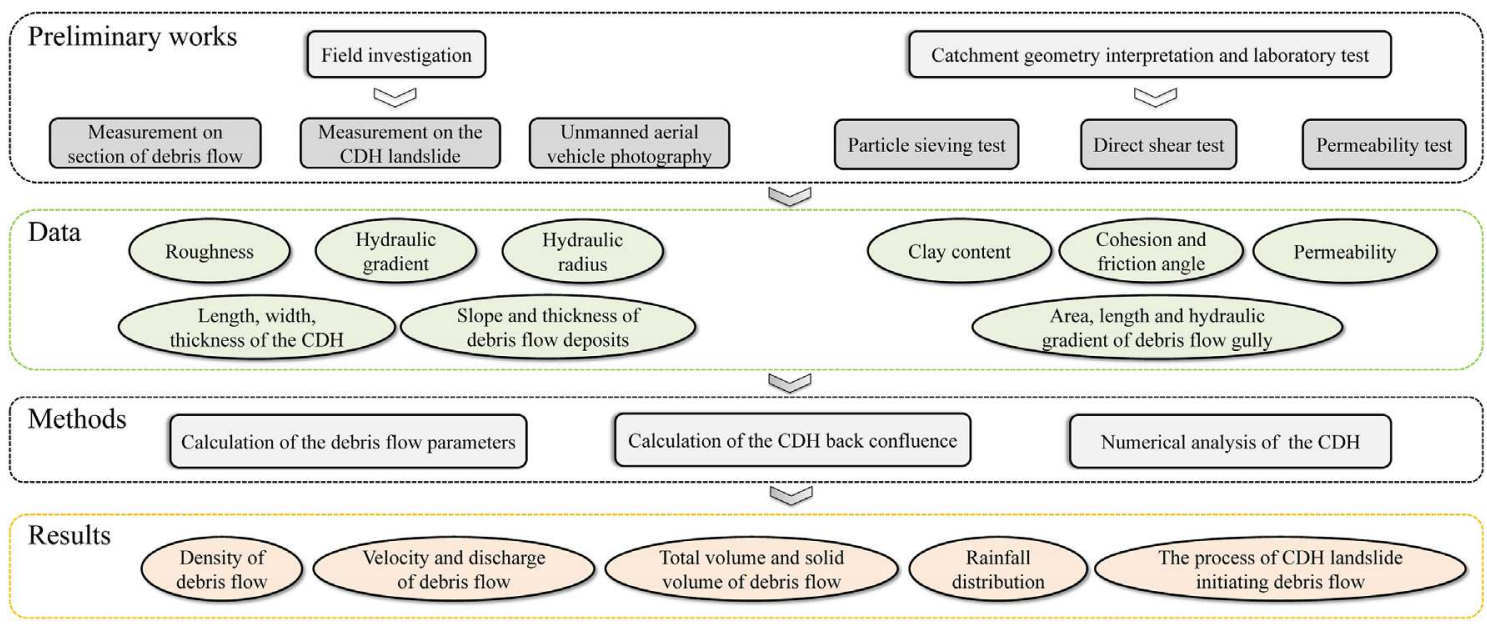

Fig. 3. Methodology used to analyse the initiation of debris flow.

\section{3.1 Field investigations, catchment geometry interpretation, and laboratory tests}

133 Field investigations were performed to ascertain the following: 1) Terrain parameters of the

134 debris flow accumulation body were evaluated through sampling at the gully mouth and

135 aerial photography using an unmanned aerial vehicle. 2) The geometric parameters of the

136 gully section such as maximum mud-mark height and widths of the section at the top and 
137 bottom. 3) Terrain parameters and the composition of the CDH landslide at the source of

138 debris flow.

139 Catchment geometry was interpreted to obtain its terrain parameters such as watershed area,

140 gully length of debris flow, and hydraulic gradient. Laboratory tests, such as particle sieve

141 analysis (Malvern), direct shear test, and permeability test, were conducted on the

142 accumulated deposits of less than $60 \mathrm{~mm}$ accumulated in the area. In addition, physical and

143 mechanical parameters of the deposits were obtained.

\section{3.2 Calculation of back-end confluence process}

145 We obtained the surface-runoff at the confluence outlet through calculations using the SCS

146 model, rational formula, and the pentagonal flow-process line method. First, the SCS model

147 was used to calculate total surface runoff. The rational formula was used to calculate hourly

148 peak-flow rate and runoff-generation time. Based on these calculations, the pentagon-flow

149 process line per hour was superimposed, and we obtained the surface-runoff process line

150 (Clark 1945; Edward Kuiper C.I. 1965; Pegram and Parak 2004). Finally, we obtained the

151 subsurface-runoff process line according to the empirical method and formed a complete-

152 runoff process line for the confluence to the $\mathrm{CDH}$.

153 The SCS model is composed of three relational equations: the equation for rainfall and runoff,

154 the water balance equation, the linear equations of initial rainfall loss. The above three

155 relational equations are combined to obtain the equations of the SCS model (Eqs. (1) and (2)). 
$156 \quad S=\frac{25400}{C N}-254$

157

$$
\left.\begin{array}{c}
Q=(P-0.2 S)^{2} /(P+0.8 S), P \geq 0.2 S \\
Q=0, P<0.2 S
\end{array}\right\}
$$

158 where $P$ refers to the total amount of rainfall $(\mathrm{mm}) ; Q$ refers to total surface runoff $(\mathrm{mm})$;

$159 S$ refers to the possible detention in the basin at that time (mm); $C N$ refers to the number of

160 runoff curves (dimensionless). The common dataset of the University of Maryland for global

161 soil cover and the simplified International Geosphere-Biosphere Programme soil cover

162 classification system were used to determine the runoff curve coefficient $C N$. Further, the

163 hydrological soil groups of A, B, C, and D were determined according to the SCS soil

164 classification.

165 The duration of runoff generation and the confluence and peak discharge were calculated by

166 the rational formula of the Chinese Academy of Water Sciences (Eqs. (3)-(8)):

$167 \tau_{0}=\left[\frac{0.278^{3 / 4}}{\frac{m J^{1 / 3}}{L}(R F)^{1 / 4}}\right]^{\frac{4}{4-n}}=\left[\frac{0.383}{\frac{m}{\theta} R^{1 / 4}}\right]^{\frac{4}{4-n}}$

$168 \psi=1-\frac{\mu}{R} \tau^{n}$

$169 \mu=3.6 F^{-0.19}$ 
$170 \tau_{c}=\left[(1-n) \frac{R}{\mu}\right]^{-\frac{1}{4-n}}$

$171 \tau=\tau_{0} \psi^{-\frac{1}{4-n}}$

$172 Q_{p}=0.278 \psi i F=0.278 \psi \frac{R}{\tau^{n}} F$

173 where $\psi$ refers to the coefficient of flood-peak discharge $\left(\mathrm{m}^{3} / \mathrm{s}\right) ; i$ refers to the maximum

174 average rainstorm intensity $(\mathrm{mm} / \mathrm{h}) ; R$ refers to the hourly rainfall $(\mathrm{mm} / \mathrm{h}) ; n$ refers to the

175 rainstorm index; $F$ refers to the confluence area $\left(\mathrm{km}^{2}\right) ; L$ refers to the gully length $(\mathrm{km}) ; J$

176 refers to the gully-bed gradient; $\tau$ refers to the watershed confluence time (h); $\tau_{0}$ refers to

177 the watershed confluence time (h) when $\psi=1 ; \tau_{c}$ refers to the runoff generation process at

178 time (h), $\mu$ refers to the runoff generation parameter, i.e., the average infiltration intensity

179 within the runoff generation process time $(\mathrm{mm} / \mathrm{h}) ; m$ refers to the confluence parameter; $Q_{p}$

180 refers to the peak discharge $\left(\mathrm{m}^{3} / \mathrm{s}\right)$. According to the survey, the rainstorm index $n=0.78$,

181 the confluence area $F=0.123 \mathrm{~km}^{2}$, the gully length of the confluence area $L=0.58 \mathrm{~km}$,

182 and the gully-bed gradient $J=591 \%$.

183 The rainstorm index was calculated by the rainstorm equation (Eqs. (9)-(11)) and was

184 considered when the confluence lasted for 1 to $6 \mathrm{~h}$.

$185 H_{1 p}=K_{p} \cdot \bar{H}_{1 p}$ 
$187 n=1+1.285 \lg \left(\frac{H_{1 p}}{H_{6 p}}\right)$

188 where, ${ }^{K}$ is a rainfall coefficient, ${ }^{H_{n p}}$ refers to $n$ hours of maximum rainfall (mm), $\bar{H}$

189 refers to the average rainfall $(\mathrm{mm})$.

190 3.3 Numerical simulation of the CDH landslide at the origin of debris flow

191 3D finite-difference software was used to calculate the dynamic response of the $\mathrm{CDH}$ under

192 seepage flow at the source of the Chenghuangmiao Gully. Seepage and deformation were

193 carried out simultaneously. The numerical model was established according to the field

194 investigation of the CDH landslide (Table 1). The model consists of colluvium deposits, the

195 bedrock, and the sliding surface, while comprising 7395 tetrahedral elements in total. The

196 coupled deformation-diffusion processes was formulated within the quasi-static Biot theory

197 framework, which can be applied to problems involving single-phase Darcy flow in a porous

198 medium. Darcy's law describes fluid transport (Eq.(12)) (Polubarinova-Kochina 1962):

$199 q_{i}=-k_{i i} \hat{k}(s)\left[p-\rho_{f} x_{j} g_{j}\right]_{, l}$

200 where ${ }^{q_{i}}$ refers to the specific discharge vector, $p$ refers to the pore pressure (Pa), $k$ refers

201 to the tensor of absolute mobility coefficients of the medium, $\hat{k}(s)$ refers to the relative 
202 mobility coefficient, which is a function of fluid saturation, $s, \rho_{f}$ refers to the fluid density

$203\left(\mathrm{~kg} / \mathrm{m}^{3}\right)$, and ${ }^{g_{j}}, i=1,3$ refers to the three components of the gravity vector.

204 The fluid mass balance is expressed as (Eq.(13)) (Biot 1956):

$205-q_{i, j}+q_{v}=\frac{\partial \zeta}{\partial t}$

206 where $^{q_{v}}$ refers to the volumetric fluid source intensity per second $\left(\mathrm{m}^{3} / \mathrm{s}\right)$, and $\zeta$ refers to

207 the variations in the fluid content or the fluid volume per unit volume of a porous material

208 due to diffusive fluid transport as introduced by Biot (1956).

209 Changes in the variation of fluid content are related to changes in pore pressure, $p$,

210 saturation, $s$, and mechanical volumetric strains, $\varepsilon$. The response equation for the pore

211 fluid is formulated as (Eq.(14)) (Keith et al. 1982):

$212 \frac{1}{M} \frac{\partial p}{\partial t}+\frac{n}{s} \frac{\partial s}{\partial t}=\frac{1}{s} \frac{\partial \zeta}{\partial t}-\alpha \frac{\partial \varepsilon}{\partial t}$

213 where $M$ refers to the Biot modulus $\left(\mathrm{N} / \mathrm{m}^{2}\right), n$ refers to porosity, and $\alpha$ refers to the Biot

214 coefficient.

215 After adding some modifications to the saturated fluid flow equation, we obtain the

216 unsaturated fluid-flow equation in coarse soils (constant air pressure and no capillary

217 pressure). The nodal volumetric flow rates in a zone $Q_{z}$ are multiplied by relative mobility,

$218 \hat{k}$ (see equation), which is a function $\left(\hat{k}\left(\hat{s}_{i n}\right)=\hat{s}_{i n}^{2}\left(3-2 \hat{s}_{i n}\right)\right.$ ) of the average saturation at the 
219 inflow nodes for the zone, $\hat{s}_{i n}$. The gravity term $\rho_{f} x_{i} g_{i}$ is multiplied by the average zone

220 saturation to account for partial zone filling. Nodal inflow rates are scaled according to local

221 saturation. For unsaturated fluid flow, the nodal volumetric flow rates in a zone $\left\{Q_{z}\right\}$ are

222 related to the nodal pore pressures $\{p\}$, which is expressed in matrix notation as (Eq. (15)):

$223\left\{Q_{z} \hat{k}\right\}=[M]\left\{p-\rho_{f} x_{i} g_{i} \bar{s}\right\}$

224 Because some updated physical and mechanical properties of soil are not considered in this

225 finite-difference software, and the sliding surface as a structural element is not affected by

226 pore pressure, the strength decreases (Ma et al. 2016; Schiliro et al. 2015). In this simulation,

227 the computer program is used to realise the change of sliding surface strength parameters

228 " $c$ " and " $\varphi$ " with saturation according to (Yang et al. 2014), which are updated every 100-

229 time steps. During the simulation, saturation, pore water pressure, and displacement of

230 different points in the $\mathrm{CDH}$ were monitored.

231 Table 1

232 Physical and mechanical parameters of rock and soil.

\begin{tabular}{ccccccccc}
\hline Type & Density & Natural & Natural & Saturated & Saturated & Shear & Permeability & Porosity \\
& $\left(\mathrm{kg}^{*} \mathrm{~m}^{-3}\right)$ & cohesion & friction & cohesion & friction & modulus & coefficient $(\mathrm{m} / \mathrm{s})$ \\
& & $(\mathrm{kPa})$ & angle $\left(^{\circ}\right)$ & $(\mathrm{kPa})$ & angle $\left(^{\circ}\right)$ & $(\mathrm{Pa})$ & & \\
\hline $\mathrm{CDH}$ & 1980 & 33.4 & 23.6 & 6.7 & 8.5 & $1.5 \mathrm{e} 6$ & $3 \mathrm{e}-5$ & 5.32 \\
Bedrock & 2201 & 2000 & 32 & & & $2.3 \mathrm{e} 10$ & $5 \mathrm{e}-10$ & 0.24 \\
\hline
\end{tabular}




\section{3.4 Process of debris flow and calculation of motion feature parameters}

234 The density of debris flow was calculated based on the clay content obtained from the soil

235 sieve analysis. We used the empirical formula of viscous debris-flow velocity to calculate

236 the flow velocity at different cross-sections based on cross-section investigation. We

237 obtained debris flow discharges at different cross-sections by combining the cross-section

238 features. According to the motion time of debris flow obtained from the survey, we used the

239 corrected pentagon method to calculate the total volume and solid volume of debris flow.

240 The density calculation method based on clay content is used to determine debris flow

241 density (Li et al. 2018) (Eq. (16)).

242

$\gamma_{c}=-1.32 \times 10^{3} x^{7}-5.13 \times 10^{2} x^{6}+8.91 \times 10^{2} x^{5}-55 x^{4}+34.6 x^{3}-67 x^{2}+12.5 x+1.55$

243 where ${ }^{\gamma_{c}}$ refers to the density of debris flow $\left(\mathrm{g} / \mathrm{cm}^{3}\right) ;{ }^{x}$ refers to the percentage of clay

244 particles $(<0.05 \mathrm{~mm})$ in the total content of particles $(<60 \mathrm{~mm})$ in the debris flow deposits.

245 The flow velocity of debris flow was calculated by the cross-section investigation. During

246 the investigation, many drop weirs, bends, and bayonets were found, which were analysed as

247 high resistance viscous debris flow, and hence, the calculation formula is (Eq. (17)) [44].

$248 V_{\mathrm{c}}=\left(1 / n_{\mathrm{c}}\right) H_{\mathrm{c}}^{2 / 3} I_{\mathrm{c}}{ }^{1 / 2}$

249 where $n_{\mathrm{c}}$ refers to the roughness coefficient; $H_{\mathrm{c}}$ refers to the average mud depth $(\mathrm{m})$; $I_{\mathrm{c}}$ refers 250 to the hydraulic gradient. 
251 By combining the flow velocity with the cross-section area, we obtained the discharge (Eq.

252 (18)):

$253 Q_{\mathrm{c}}=A_{\mathrm{sc}} * V_{\mathrm{c}}$

254 where $A_{\text {sc }}$ refers to cross-section area $\left(\mathrm{m}^{2}\right) ; V_{\mathrm{c}}$ refers to the velocity of debris flow of the

255 section $(\mathrm{m} / \mathrm{s})$.

256 We calculated the total volume of this continuous debris flow, and the modified Pentagon

257 method was used for the calculation [44]. According to the process time $T$ and the maximum

258 flow $Q_{\mathrm{c}}$ of debris flow, the total volume of debris flow $W_{\mathrm{c}}$ is calculated by $W_{\mathrm{c}}=K T Q_{\mathrm{c}}$. The

259 solid volume of debris flow is calculated as follows (Eq. (19)):

$260 W_{S}=C_{V} W_{C}=\left(\gamma_{C}-\gamma_{w}\right) W_{C} /\left(\gamma_{S}-\gamma_{w}\right)$

261 where $W_{S}$ refers to the solid volume of debris flow passed through the calculated section

$262\left(\mathrm{~m}^{3}\right) ; C_{V}$ refers to the volume concentration of the soil in the debris flow.

2634 Features of debris flow in the Chenghuangmiao Gully

\section{4.1 Features of debris-flow disaster}

265 The Chenghuangmiao Gully debris-flow disaster was a giant low-frequency viscous

266 continuity delayed debris-flow disaster in a small watershed (Table 2).

267 Table 2

268 Parameters of debris flow in the Chenghuangmiao Gully. 


\begin{tabular}{ccccccc}
\hline Features & $\begin{array}{c}\text { Watershed } \\
\left(\mathrm{m}^{3}\right)\end{array}$ & $\begin{array}{c}\text { Peak discharge at } \\
\text { mountain pass }\left(\mathrm{m}^{3} / \mathrm{s}\right)\end{array}$ & $\begin{array}{c}\text { Frequency } \\
(\text { year/ once })\end{array}$ & $\begin{array}{c}\text { Density } \\
\left(\mathrm{g} / \mathrm{cm}^{3}\right)\end{array}$ & $\begin{array}{c}\text { Delay behind } \\
\text { rainfall stop }(\mathrm{h})\end{array}$ & $\begin{array}{c}\text { Death } \\
(\text { person })\end{array}$ \\
\hline Value & 6.10 & 290.4 & $1 \%$ & 1.807 & 3.67 & 4 \\
\hline Property & Small & Giant & Low frequency & Viscosity & Delayed & Disaster \\
\hline
\end{tabular}

269 While the Chenghuangmiao Gully debris flow is recognised as a disaster, it is also a

270 geological process controlled by spatial distribution and temporal evolution features. The

271 horizontal and longitudinal sections of the Chenghuangmiao Gully show that it can be

272 divided into the $\mathrm{CDH}$ landslide at the gully source, initiation-circulation area, and

273 accumulation area (Fig. 4). After spatiotemporal considerations, we obtained the

274 accumulation and motion features of debris flow and the dynamic features of landslides at the

275 origin of the debris flow (the initiation process of debris flow).

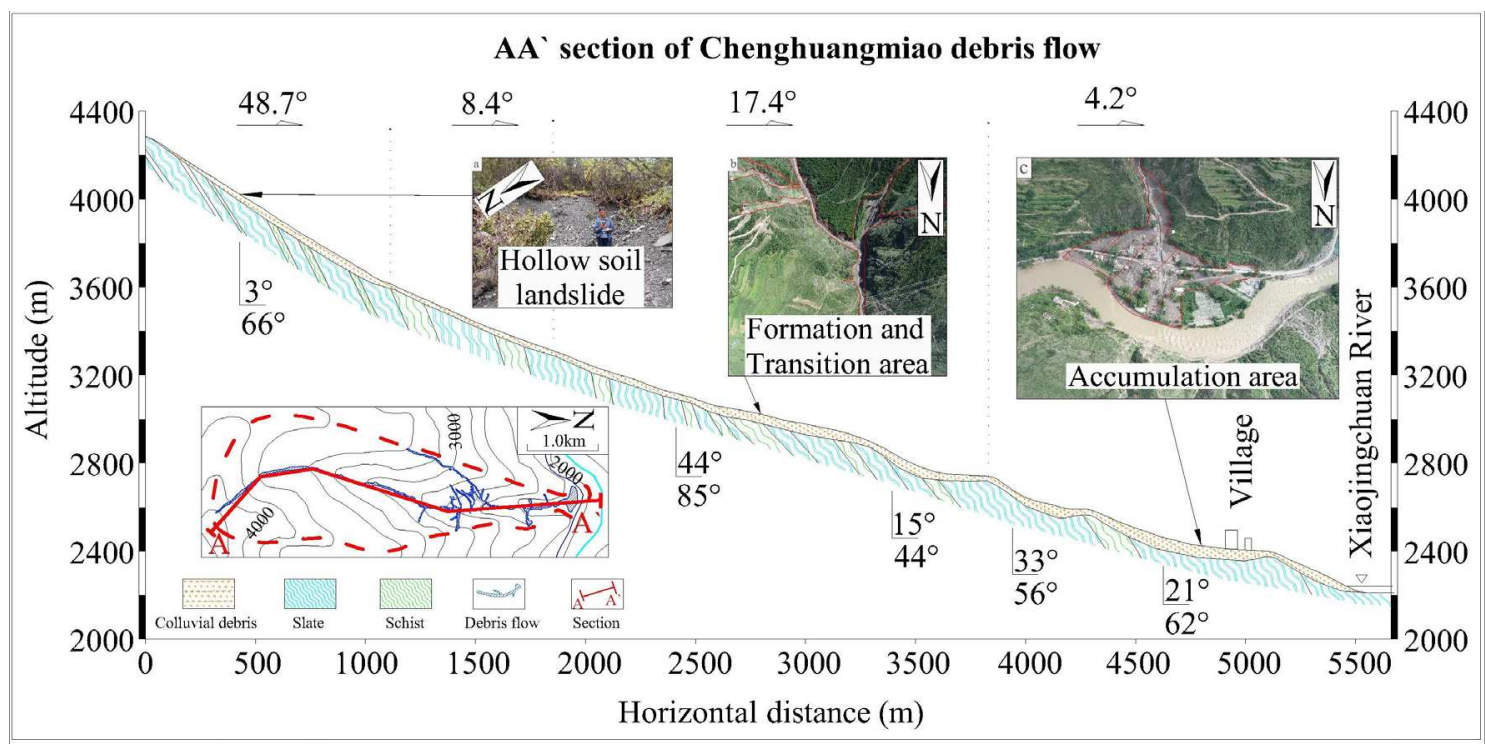

277 Fig. 4. Plan and longitudinal section of the Chenghuangmiao Gully: (a) CDH landslide at the

278 source of the Chenghuangmiao Gully; (b) Transition area; (c) Accumulation area. 


\section{$279 \quad 4.2$ Accumulation features of debris flow}

280 The debris flow experienced approximately 25 min of accumulation. After approximately $2813200 \mathrm{~m}^{3}$ of debris-flow solid material was washed into the Xiaojinchuan river, the debris-

282 flow accumulation body of approximately $369.2 \mathrm{~m}$ in length, $198.3 \mathrm{~m}$ in width, $3222.8 \mathrm{~m}^{2}$ in 283 area, $1.4-6.7 \mathrm{~m}$ in thickness, $159 \%$ in longitudinal gradient, and $18100 \mathrm{~m}^{3}$ of solid volume

284 (Fig. 5a-c) was formed. The deposits in the accumulation body were composed of slate and 285 schist fragments and clay. The deposits were well sorted, with $2.35 \%$ clay content and the 286 maximum boulder size was $3.0 \times 2.7 \times 1.8 \mathrm{~m}$ (Fig. $5 \mathrm{~b}$ and Fig. 6).

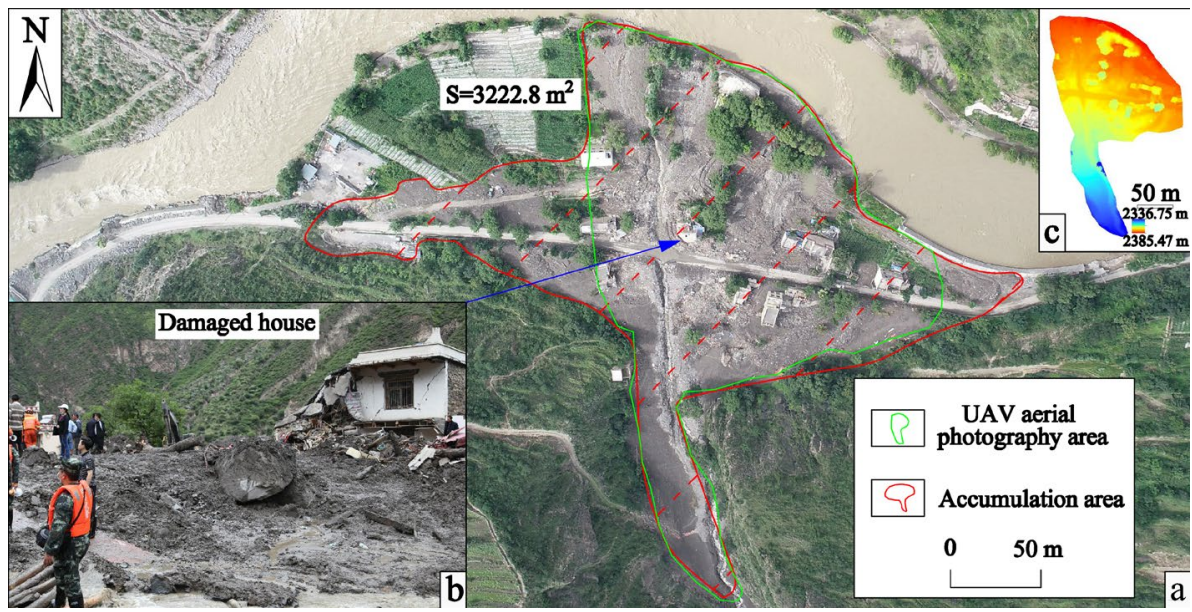

288 Fig. 5. Accumulation area: (a) Accumulation area; (b) Washed-out houses; (c) Altitude 289 image. 


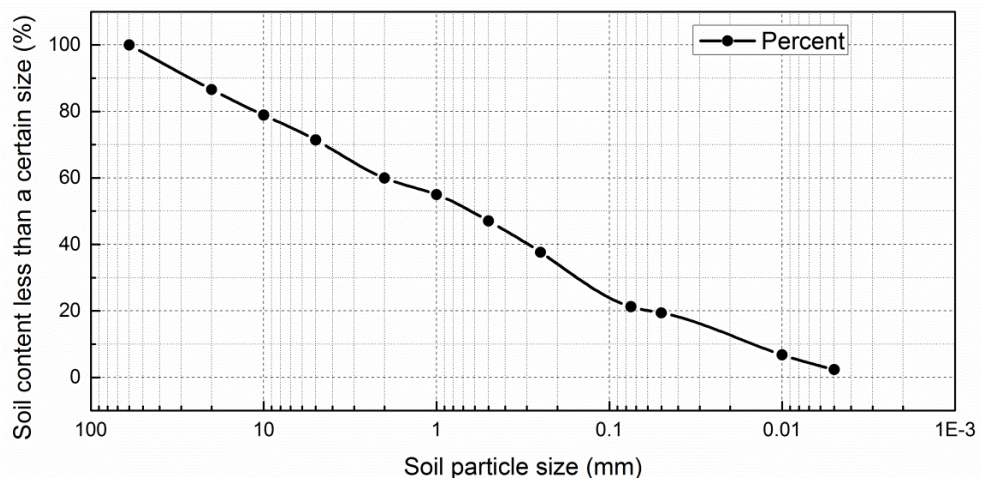

Fig. 6. Debris flow accumulation particle curve.

\subsection{Motion features and process of debris flow}

293 The debris in the Chenghuangmiao Gully had a high density. There was an increase in the

294 initial velocity of debris flow and a later decrease, and a slow increase in its discharge. The

295 motion feature parameters were obtained through cross-section investigations, laboratory

296 tests, and theoretical model calculations. By incorporating $2.35 \%$ of clay content into the

297 empirical formula, we obtained a bulk density of $1.807 \mathrm{~g} / \mathrm{cm}^{3}$ for the debris flow. Based on 298 mud-mark height and gully-bed gradient obtained from the investigation of the debris-flow 299 gully, the viscous debris-flow velocity calculation formula (Eq. (16)) was used to obtain the 300 debris-flow peak velocity of $3.39-5.20 \mathrm{~m} / \mathrm{s}$ (Table 3 ). Based on the cross-sectional area

301 obtained by the cross-sectional survey, the debris flow at different cross-sections was 302 calculated by (Eq. (17)). The peak debris flow was $57.6-290.4 \mathrm{~m}^{3} / \mathrm{s}$, with the maximum

303 occurring at the mountain pass (Fig. 7 and Table 3). Using the modified Pentagon method 304 (Eq. (18)) to calculate the total volume of debris flow, the total amount of debris flow $W_{\mathrm{c}}$ was 
305 approximately $43995.6 \mathrm{~m}^{3}$, and the solid volume $W_{\mathrm{s}}$ was approximately $21260.2 \mathrm{~m}^{3}$.

306 According to the investigation results, the total process time of debris flow was 25 min and

307 the watershed area was $6.1 \mathrm{~km}^{2}$. The gully bed was rough and its average gradient was $375 \%$,

308 and hence, $K=0.0378$ and $1 / n_{\mathrm{c}}=2.57$ in Eq. (17).

\section{Table 3}

310 The results of the calculation of flow by the morphological method.

\begin{tabular}{ccccccc}
\hline Number & Section position & $\begin{array}{c}\text { Hydraulic } \\
\text { gradient }\end{array}$ & $\begin{array}{c}\text { Maximum mud } \\
\text { depth }(\mathrm{m})\end{array}$ & $\begin{array}{c}\text { Area } \\
\left(\mathrm{m}^{2}\right)\end{array}$ & $\begin{array}{c}\text { Velocity } v_{\mathrm{c}} \\
\left(\mathrm{m}^{\circ} \mathrm{s}^{-1}\right)\end{array}$ & $\begin{array}{c}\text { Peak discharge } \\
\left(\mathrm{m}^{\circ} \bullet \mathrm{s}^{-1}\right)\end{array}$ \\
\hline 1 & $102^{\circ} 10^{\prime} 38.16^{\prime \prime}, 30^{\circ} 59^{\prime} 18.56^{\prime \prime}$ & 0.68 & 2.1 & 17.0 & 3.39 & 57.6 \\
2 & $102^{\circ} 10^{\prime} 36.11^{\prime \prime}, 30^{\circ} 59^{\prime} 20.71^{\prime \prime}$ & 0.68 & 2.3 & 18.5 & 3.69 & 68.3 \\
3 & $102^{\circ} 10^{\prime} 31.71^{\prime \prime}, 30^{\circ} 59^{\prime} 24.50^{\prime \prime}$ & 0.82 & 2.5 & 18.0 & 4.06 & 77.2 \\
4 & $102^{\circ} 10^{\prime} 16.14^{\prime \prime}, 31^{\circ} 0^{\prime} 23.00^{\prime \prime}$ & 0.34 & 4.6 & 29.1 & 4.15 & 120.5 \\
5 & $102^{\circ} 10^{\prime} 21.36^{\prime \prime}, 31^{\circ} 0^{\prime} 26.24^{\prime \prime}$ & 0.29 & 5.2 & 34.2 & 4.15 & 141.9 \\
6 & $102^{\circ} 10^{\prime} 31.16^{\prime \prime}, 31^{\circ} 0^{\prime} 49.05^{\prime \prime}$ & 0.21 & 7.2 & 53.5 & 4.39 & 234.9 \\
7 & $102^{\circ} 10^{\prime} 31.67^{\prime \prime}, 31^{\circ} 0^{\prime} 49.63^{\prime \prime}$ & 0.55 & 4.5 & 49.2 & 5.20 & 255.6 \\
8 & $102^{\circ} 10^{\prime} 32.73^{\prime \prime}, 31^{\circ} 1^{\prime} 51.22^{\prime \prime}$ & 0.27 & 6.2 & 58.0 & 4.68 & 270.9 \\
\hline & $102^{\circ} 10^{\prime} 32.35^{\prime \prime}, 31^{\circ} 1^{\prime} 53.09^{\prime \prime}$ & 0.36 & 4.3 & 66.2 & 4.39 & 290.4 \\
\hline
\end{tabular}

311 The motion of debris flow in the main gully was a gradually increasing process of discharge,

312 which took approximately $19.5 \mathrm{~min}$. From section (1) (about $0.01 \mathrm{~km}$ away from the CDH

313 confluence outlet) (Fig. 8) to section (9) (at the mountain pass), the discharge slowly

314 increased from $57.6 \mathrm{~m}^{3} / \mathrm{s}$ to $270.4 \mathrm{~m}^{3} / \mathrm{s}$. Combined with the average velocity of $4.23 \mathrm{~m} / \mathrm{s}$ and

315 the gully length of $4.95 \mathrm{~km}$, the time of the debris flow was calculated at approximately 19.5

$316 \mathrm{~min}$. 
317 Between section (4) (about $2 \mathrm{~km}$ away from the outlet of the $\mathrm{CDH}$ confluence) and section

318 (7) (about $3 \mathrm{~km}$ away from the outlet of the $\mathrm{CDH}$ confluence), the discharge process line

319 became steeper (discharge increased from $141.9 \mathrm{~m}^{3} / \mathrm{s}$ to $234.9 \mathrm{~m}^{3} / \mathrm{s}$ ). By combining the

320 increase in the hydraulic gradient observed by the two sections (increased from

321 approximately $340 \%$ to approximately $550 \%$ ), the expansion of the sectional area, and the

322 rise in the thickness of the loose deposits, we found that the increase in discharge was due to

323 an increase in the hydraulic gradient and material sources. The debris flow in the

324 Chenghuangmiao Gully was not limited or blocked (Fig. 7).

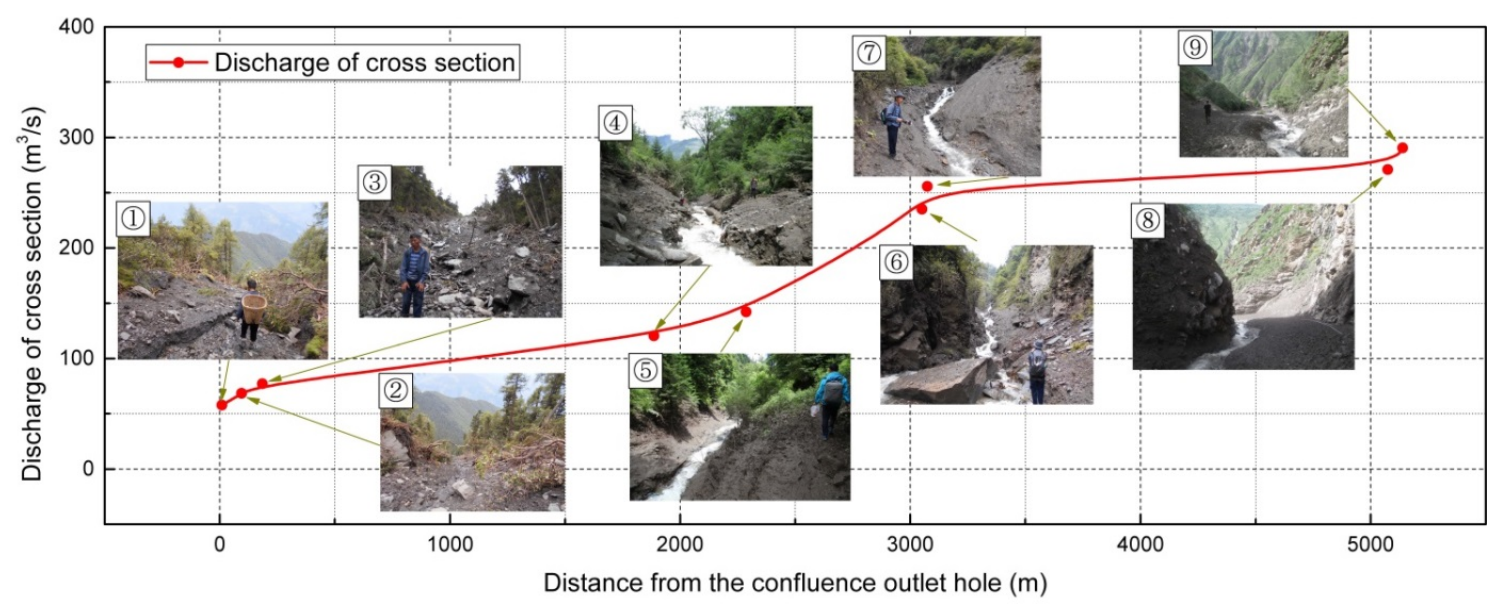

Fig. 7. Debris flow discharge process.

\section{4.4 Features of the CDH landslide at the origin of debris flow}

328 The CDH landslide at the origin of debris flow was a small shallow soil landslide. The

329 landslide was located at the outlet of the $\mathrm{CDH}$ confluence area $\left(102^{\circ} 10^{\prime} 38.16^{\prime \prime}\right.$ and $\left.33030^{\circ} 59^{\prime} 18.56^{\prime \prime}\right)$ at an altitude of $4060 \mathrm{~m}$ (Fig. 8a). The slide body was composed of crushed 
331 rock and soil. The length, width, thickness, area, and volume of the slide body were $25.0 \mathrm{~m}$,

$33212.3 \mathrm{~m}, 1.1-1.8 \mathrm{~m}, 296 \mathrm{~m}^{2}$, and $362 \mathrm{~m}^{3}$, respectively. The angle between the sliding direction $333\left(337^{\circ}\right)$ and bedrock inclination $\left(3^{\circ}\right)$ was $26^{\circ}$. The sliding surface was the interface of bedrock

334 and deposits. The trailing edge was $7.7 \mathrm{~m}$ long and the slope was $45^{\circ}$ (Fig. 8b-h). The

335 bedrock occurred on the slide bed at an angle of $3^{\circ}<66^{\circ}$. Slate and schist alternately

336 appeared, the slate was bent, sericite was seen on the layer, scratches were developed, schist

337 joints were broken, and the water flowed along with the schist layer towards the toe of the

$338 \mathrm{CDH}$ (Fig. 8b-d). The hole at the $\mathrm{CDH}$ confluence outlet was located at the junction of the

339 rear edge and the left boundary. The soil on the upper part of the outlet had not sunk owing to

340 the development of moss, the outlet hole was $2.4 \mathrm{~m}$ wide, the highest was at $0.8 \mathrm{~m}$, and the

341 lowest was at $0.5 \mathrm{~m}$ and the cross-sectional area was $1.56 \mathrm{~m}^{2}$ (Fig. $8 \mathrm{c}$ ). With the downward

342 sliding of the landslide, a bedrock block appeared on the landslide's right boundary, which

343 decreased by $4.8 \mathrm{~m}$ horizontally, and the left boundary of the landslide widened by $2.1 \mathrm{~m}$

344 southwest (Fig. 8e). 


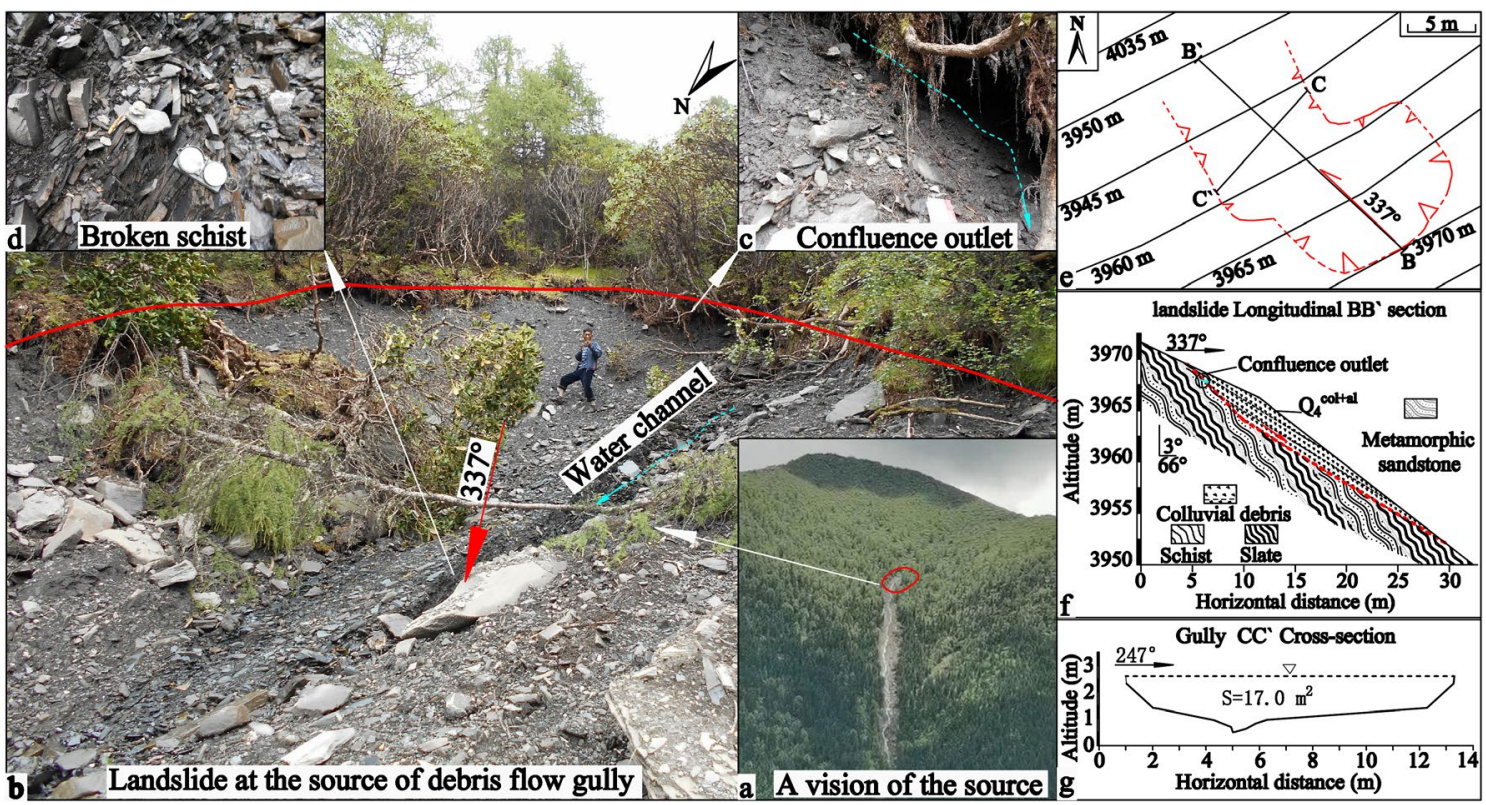

346 Fig. 8. The $\mathrm{CDH}$ landslide at the source of the debris-flow gully; (a) The location of the $\mathrm{CDH}$

347 landslide at the source of the gully; (b) The trailing edge of the CDH landslide at the source

348 of the gully and the slide bed; (c) The bedrock on the slide bed; (d) The confluence outlet; (e)

349 Landslide plan; (f) Landslide profile; (g) Landslide cross-section.

\section{Initiation of delayed debris flow}

351 The initiation of debris flow was delayed by the landslide process of the $\mathrm{CDH}$ at the back-end

352 confluence. Rainfall mainly converged on to the $\mathrm{CDH}$ in the form of surface and subsurface

353 runoff. Under the effect of water infiltration, the saturation and pore pressure of the $\mathrm{CDH}$

354 increased, the intensity decreased, and instability occurred resulting in the landslide, and that

355 initiated the debris flow. The whole process took 9 h 20 min from 18:00 h on 5 July 2020 to

$35603: 20$ h on 6 July 2020. 
357 The reasons for the occurrence of debris flow in the Chenghuangmiao Gully $3 \mathrm{~h} 40$ min after

358 the rainfall stopped is as follows: Rainfall and confluence infiltrations during the rainfall

359 could not sufficiently increase the pore pressure of the $\mathrm{CDH}$ and weaken it to cause

360 instability. The seepage process continued for $3 \mathrm{~h} 20 \mathrm{~min}$ inside the $\mathrm{CDH}$ after the rainfall

361 stopped. That was sufficient to increase the pore pressure of the $\mathrm{CDH}$ and reduce its strength

362 causing instability, thereby initiating the debris flow.

\subsection{Surface runoff and subsurface flow process at the back end of the CDH}

364 The back-end confluence was the rainfall entering the $\mathrm{CDH}$ in the form of surface and

365 subsurface runoff. The effective rainfall amount that was transformed into surface and

366 subsurface runoff before the disaster was $32 \%$. The confluence lasted approximately $5.76 \mathrm{~h}$,

367 and the peak flow was $0.125 \mathrm{~m}^{3} / \mathrm{s}$ at $21: 42$ on 5 July 2020 , and the rest of the rainfall was

368 intercepted and evaporated by moss litter and others.

369 The above data were obtained by the following calculation or empirical method: 1) Using the

370 SCS model to calculate the effective rainfall $(17 \mathrm{~mm})$ from 18:00 to 24:00 h on 5 July 2020

371 produced a total surface runoff of $2.729 \mathrm{~mm}$, that is, surface runoff accounted for $16.05 \%$ of

372 the total rainfall (Eqs. (1) and (2)); 2) Based on the rational formula (Eqs. (3)-(11)), the five-

373 hours peak flow and runoff time were obtained (Table 4); 3) By combining 16.05\% runoff

374 yield ratio, peak flow, and runoff time, the pentagon process line was used to generalise the

375 surface-runoff process per hour, and then, the surface runoff flow process line was obtained; 
376 4) According to results of the experimental research on surface and subsurface runoff

377 conducted by Li et al., the process of subsurface runoff was similar to the process of surface

378 runoff, and the delay was $26.5 \mathrm{~min}$ in the study area (Li et al. 2010; Zhang et al. 2015), and

379 then, we obtained the subsurface-runoff process line according to the surface-runoff process

380 line; 5) By superimposing the surface-runoff process line and the subsurface-runoff process

381 line, the runoff process of the confluence at the back end of the $\mathrm{CDH}$ was obtained (Fig. 9a);

382 6) Based on the research of Ye et al., the interception of the moss litter layer with a thickness

383 of $9.8 \mathrm{~cm}$ in the study area accounted for approximately $42 \%$ of the total rainfall (Wang et al.

384 2010; Ye et al. 2004). Finally, the pie chart of the rainfall distribution was prepared (Fig. 9b).

385

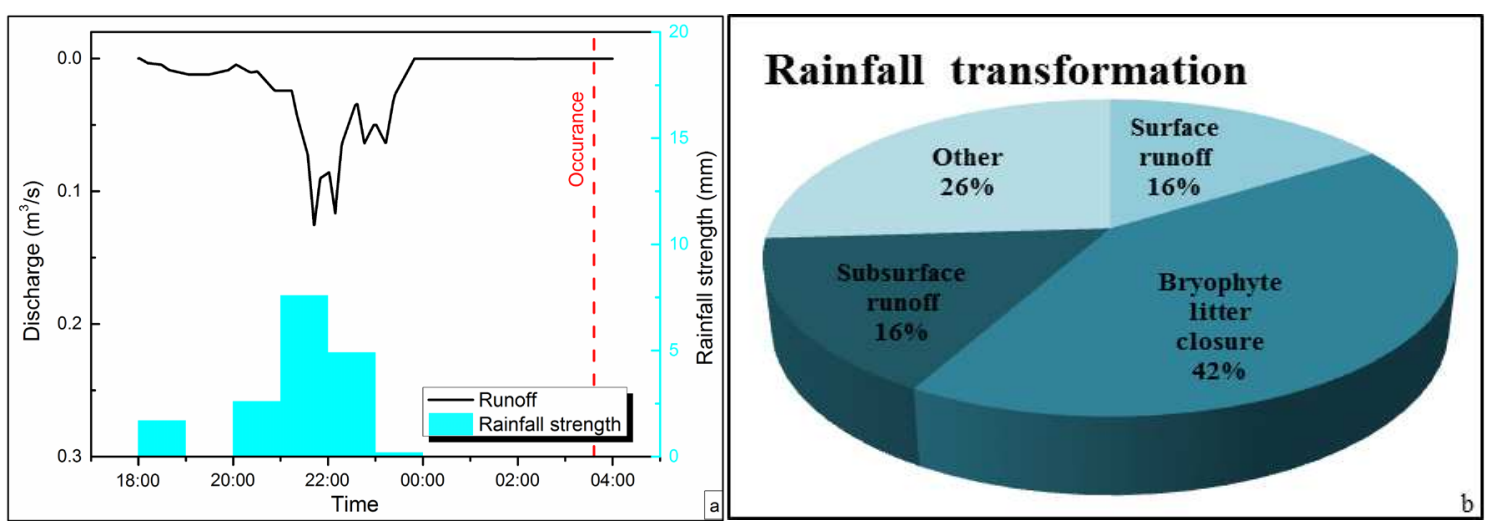

386 Fig. 9. Rainfall and runoff: (a) Runoff process line at the back end of the $\mathrm{CDH}$; (b) Rainfall

387 transformation pie chart.

388 Table 4

389 Results of the calculations of confluence parameters using the rational formula. 


\begin{tabular}{ccccc}
\hline Time & Peak discharge $Q_{\mathrm{p}}\left(\mathrm{m}^{3} \cdot \mathrm{s}^{-1}\right)$ & Surface runoff $\left(\mathrm{m}^{3}\right)$ & Runoff generation time $\tau_{\mathrm{c}}(\mathrm{h})$ & Confluence time $\tau(\mathrm{h})$ \\
\hline 19:00 & 0.0069 & 33.56 & 0.035 & 2.029 \\
$20: 00$ & 0.0000 & 0.00 & 0.000 & 0.000 \\
$21: 00$ & 0.0157 & 51.33 & 0.064 & 1.651 \\
$22: 00$ & 0.1141 & 150.04 & 0.236 & 0.935 \\
$23: 00$ & 0.0538 & 96.73 & 0.162 & 1.210 \\
$24: 00$ & 0.0001 & 0.98 & 0.002 & 5.864 \\
\hline
\end{tabular}

\subsection{Initiation of debris flow induced by CDH landslide}

391 The initiation of debris flow was caused by an increase in the pore water pressure of the CDH

392 and decrease in its strength after the confluence and rainfall infiltration, and the CDH

393 landslide entered the accelerated deformation stage. The rainfall from 18:00 to 24:00 h on 5

394 July 2020 caused surface and subsurface runoff to continuously converge into the CDH; on

395 saturation, the $\mathrm{CDH}$ expanded rapidly along with the base interface to the leading edge,

396 causing the pore pressure of the soil near the base interface to increase. The rain stopped from

397 00:00 to $03: 20 \mathrm{~h}$ on 6 July 2020, and the expansion of the saturation range of the CDH

398 became slower, and eventually it made the soil near the leading edge and base interface

399 saturated, thereby decreasing the soil strength, causing the CDH landslide, and subsequently

400 initiating the debris flow.

401 The changes in soil saturation, pore water pressure, and displacement reflected the changes in 402 the soil's state. Saturation at Point 1 in the trailing edge of CDH, Point 2 in the near-surface 403 of the middle part of $\mathrm{CDH}$, and Point 3 in the near base interface of the middle part of $\mathrm{CDH}$ 404 increased first, and then, remained stable. Point 3 reached saturation first. Saturation at Point 
4054 was rising throughout the process, and the range of saturation expanded, and at 406 approximately 03:20 $\mathrm{h}$ the saturation at each point increased sharply (Fig. 10a, Fig. 11a-c).

407 The changes in pore pressure and saturation were similar. Pore pressure at Point 3 increased 408 the fastest, from $0.0 \mathrm{kPa}$ to $7.2 \mathrm{kPa}$, while the pore pressure at the other points increased 409 slowly and decreased sharply at approximately 03:20 h. During the whole process, the value 410 of pore pressure increased and the range of positive pore pressure increased (Fig. 10b, Fig. $41111 \mathrm{e}-\mathrm{g})$. These changes in saturation and pore pressure caused the near base interface part of 412 the $\mathrm{CDH}$ to become the main seepage channel. The seepage channel caused the continuous 413 infiltration in the leading edge of the CDH. The strength at the leading edge and the soil near 414 the base interface of the $\mathrm{CDH}$ reduced resulting in the landslide. The displacement of the 415 monitoring points shows the process of landslide instability and deformation that initiated the 416 debris flow. The displacement of each point of the $\mathrm{CDH}$ showed an increasing trend during 417 and after the rain stopped and increased by $0.03,0.25,0.26,0.26 \mathrm{~m}$ respectively at the four 418 points at $02: 00 \mathrm{~h}$ on 6 July 2020 . After $02: 00 \mathrm{~h}$ on 6 July 2020 the displacement at each point 419 increased sharply. The rate of displacement at each point from 02:18 to 02:50 h decreased 420 slightly, and the displacement curve showed a stable and rapid increase from 02:50 to 03:20 $\mathrm{h}$ 421 (Fig. 10c, Fig. 11g-i). According to (Azimi et al. 1988; Tavenas and Leroueil 1981), we 422 divided the stages of slope deformation and failure. We found that the initial deformation 
423 stage occurred from 02:00 to $02: 18 \mathrm{~h}$, the secondary deformation stage occurred from 02:18

424 to $02: 50 \mathrm{~h}$, and the accelerated deformation stage occurred from 02:50 to $03: 20 \mathrm{~h}$.
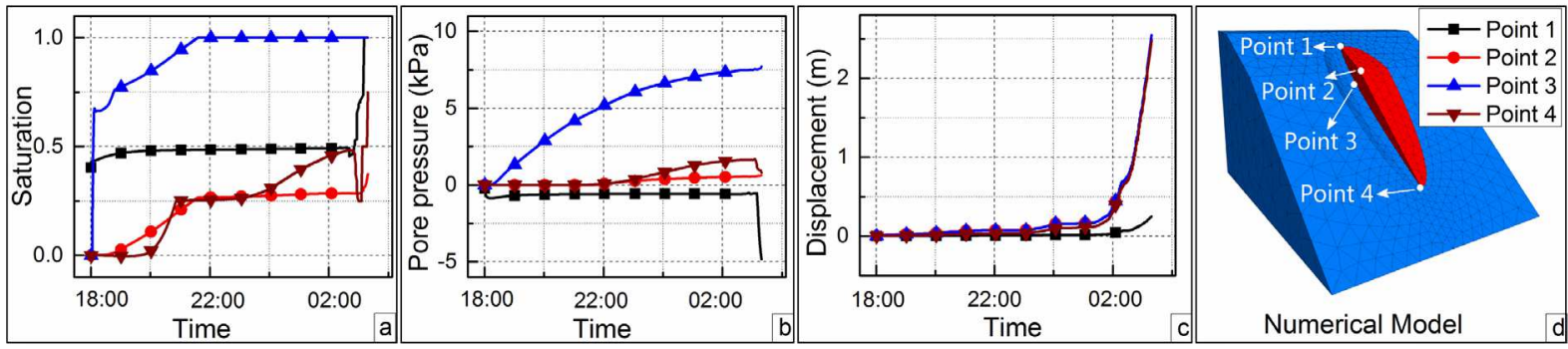

426 Fig. 10. Variation of the $\mathrm{CDH}$ parameters at different locations with time: (a) Soil saturation

427 variation curve; (b) Pore water pressure variation curve; (c) Deformation displacement 428 variation curve; (d) Numerical model.
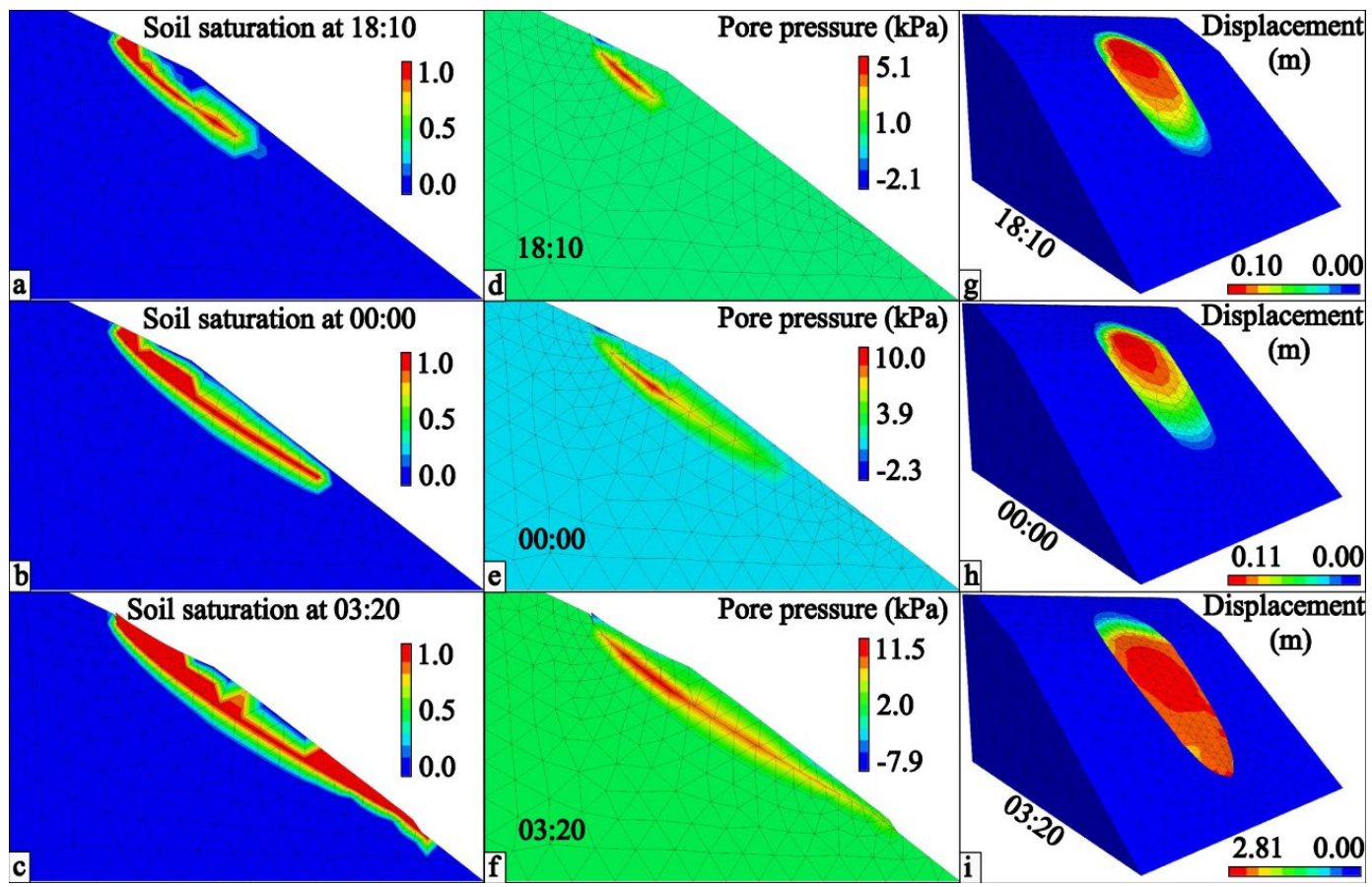
430 Fig. 11. The $\mathrm{CDH}$ landslide simulation results: (a) Soil saturation at 18:10 h; (b) Soil

431 saturation at 00:00 h; (c) Soil saturation at 03:20 h; (d) Pore water pressure distribution at

432 18:10 h; (e) Pore pressure distribution at 00:00 h; (f) Pore pressure distribution at 03:20 h; (g)

433 Total soil deformation at 18:10 h; (h) Total soil deformation at 00:00 h; (i) Total soil 434 deformation at 03:20 h.

435 The debris flow reached the gully mouth at $03: 40 \mathrm{~h}$ by filed investigation, and the debris 436 flow took $19.5 \mathrm{~min}$ by calculation; hence, the debris flow was initiated at about 03:20 $\mathrm{h}$.

437 Therefore, the accuracy of the simulation was verified.

\section{Conclusions and Discussions}

439 Since 18:00 h on 5 July 2020, rainfall mainly converged into the $\mathrm{CDH}$ in the form of surface 440 and subsurface runoff, and the pore pressure of the $\mathrm{CDH}$ increased and its strength decreased. 441 At 02:00 h on 6 July 2020, the $\mathrm{CDH}$ showed obvious deformation signs and entered the 442 initial deformation stage of the landslide. At $03: 20$ h on 6 July 2020, the displacement of each 443 point of the $\mathrm{CDH}$ increased sharply, the $\mathrm{CDH}$ landslide entered the accelerated deformation 444 stage, and the debris flow was initiated. At 03:40 h on 6 July 2020, viscous debris flow 445 experienced a gradual increase in its discharge motion for approximately $19.5 \mathrm{~min}$, reaching 446 Yuanying Village, Xiaojin County. At 04:05 on 6 July 2020, the debris flow that lasted for 25 447 min ended, causing 4 deaths and 27 injuries. 
448 We studied the delayed debris flow that occurred recently in the Chenghuangmiao Gully at

449 Aba Prefecture of Sichuan Province. Through field investigations, laboratory tests, theoretical

450 calculations, and fluid--solid coupling numerical simulation based on Biot theory, the motion

451 features and the initiation of the debris flow were analysed based on surface and subsurface 452 runoff (at the back end), and the instability and landslide process of the CDH. Therefore, the

453 following conclusions were reached.

454 (1) The Chenghuangmiao Gully debris-flow disaster was a giant viscous continuous 455 delayed low-frequency debris-flow disaster in a small watershed. The density of the debris 456 flow was $1.807 \mathrm{~g} / \mathrm{cm}^{3}$, which occurs only once in a century by investigation. The maximum 457 velocity of the debris flow was $5.2 \mathrm{~m} / \mathrm{s}$, max discharge at the mountain pass was $290.4 \mathrm{~m}^{3} / \mathrm{s}$, 458 and debris flow volume was approximately $44,000 \mathrm{~m}^{3}$.

459 (2) The CDH landslide at the source of the Chenghuangmiao Gully was a small shallow 460 soil landslide. The sliding direction of the landslide was $337^{\circ}$, and its sliding surface was the 461 base interface; it exhibited an area of $296 \mathrm{~m}^{2}$, with the sliding volume being $362 \mathrm{~m}^{3}$.

462 (3) The initiation of debris flow was represented by the delayed landslide process of the $463 \mathrm{CDH}$ under the influence of back-end confluence. Rainfall flowed into the CDH in the form 464 of surface and subsurface runoff. The pore pressure of the $\mathrm{CDH}$ rose, and its strength 465 decreased. The $\mathrm{CDH}$ landslide entered the accelerated deformation stage to initiate debris 466 flow. The whole process took $9 \mathrm{~h}$ and $20 \mathrm{~min}$. 
467 (4) The motion of debris flow in the main gully represented a process that slowly

468 increased discharge, which took approximately $19.5 \mathrm{~min}$.

469 (5) Rainfall and confluence infiltration were insufficient to reduce the pore pressure and

470 increase instability of the $\mathrm{CDH}$, thereby causing the delay in debris flow. After the rainfall 471 stopped, the seepage process continued for $3 \mathrm{~h} 20 \mathrm{~min}$ inside the soil, and it increased the

472 pore pressure of the soil sufficiently and reduced the strength of the $\mathrm{CDH}$ to initiate the debris 473 flow.

474 The evacuation of personnel from vulnerable areas should form the core of the process of 475 prevention and mitigation of a debris-flow disaster event. There is a need to perform 476 comprehensive disaster investigation, provide measures for active prevention, identify and 477 control hidden danger points, achieve passive relocation, and execute continuous monitoring 478 of debris flow confluence area (Shimizu area), which can effectively reduce the losses caused 479 by delayed debris flow. The investigation of debris-flow gully in the confluence area 480 (Shimizu area) is required. After identifying the hidden dangers of geological disasters and 481 assessing the disaster risks, timely, preventive, and passive avoidance measures must be 482 undertaken. When rainfall occurs at the hidden point and disappears for a few hours, it is 483 necessary to continuously monitor the debris-flow source area and confluence area (Shimizu 484 area) afterward, and issue early warnings in time. Finally, strengthening of the management 
within the danger zone before the disaster occurs.

487

\section{Acknowledgements}

This work was supported by the National Key Research and Development Program of China [grant number 2018YFC1505202]; the National Natural Science Foundation of China [gran t number U20A20110 ]; and the Youth Innovation Promotion Association CAS [grant numb er 2020367].

\section{Declaration of interests}

The authors declare that they have no known competing financial interests or personal relati onships that could have appeared to influence the work reported in this paper.

\section{References}

Alfieri L, Laio F, Claps P (2008) A simulation experiment for optimal design hyetograph selection Hydrological Processes 22:813-820 doi:10.1002/hyp.6646

Azimi C, Biarez J, Desvarreux P, Keime F Prevision d'eboulement en terrain gypseux. In: International symposium on landslides. 5, 1988. pp 531-536

Baum RL, Godt JW (2010) Early warning of rainfall-induced shallow landslides and debris flows in the USA Landslides 7:259-272 doi:10.1007/s10346-009-0177-0

Biot MA (1956) General solutions of equations of elasticity and consolidation for a porous material Journal of Applied Mechanics 23:91-96

Cannon SH, Boldt EM, Laber JL, Kean JW, Staley DM (2011) Rainfall intensity-duration thresholds for postfire debris-flow emergency-response planning Natural Hazards 59:209-236 doi:10.1007/s11069-011-97472

Cannon SH, Gartner JE, Wilson RC, Bowers JC, Laber JL (2008) Storm rainfall conditions for floods and debris flows from recently burned areas in southwestern Colorado and southern California Geomorphology 96:250-269 doi:10.1016/j.geomorph.2007.03.019

Chen N, Zou Q, Su F, Cui P, Zhang Y (2015) Risk assessment and disaster reduction strategies for mountainous and meteorological hazards in Tibetan Plateau Chinese Science Bulletin 60:3067-3077 doi:10.1360/n972015-00849

Chen NS, Yue ZQ, Cui P, Li ZL (2007) A rational method for estimating maximum discharge of a landslideinduced debris flow: A case study from southwestern China Geomorphology 84:44-58 doi:https://doi.org/10.1016/j.geomorph.2006.07.007

Clark CO (1945) STORAGE AND THE UNIT HYDROGRAPH Transactions of the American Society of Civil Engineers 110:1419-1446 
Crosta GB, Dal Negro P (2003) Observations and modelling of soil slip-debris flow initiation processes in pyroclastic deposits: the Sarno 1998 event Natural Hazards and Earth System Sciences 3:53-69 doi:10.5194/nhess-3-53-2003

Deng QL, Zhu ZY, Cui ZQ, Wang XP (2000) Mass rock creep and landsliding on the Huangtupo slope in the reservoir area of the Three Gorges Project, Yangtze River, China Engineering Geology 58:67-83 doi:10.1016/s0013-7952(00)00053-3

Edward Kuiper C.I. SM, P.Eng., F.ASCE, MEIC (1965) Water Resources Development. Springer US,

Feng Z, Cui P, He S (2005) Mechanism of conversion of landslides to debris flows Journal of Natural Disasters 14:8-14

Guzzetti F, Peruccacci S, Rossi M, Stark CP (2008) The rainfall intensity-duration control of shallow landslides and debris flows: an update Landslides 5:3-17 doi:10.1007/s10346-007-0112-1

Hua JP, Liang ZM, Yu ZB (2003) A modified rational formula for flood design in small basins Journal of the American Water Resources Association 39:1017-1025 doi:10.1111/j.1752-1688.2003.tb03689.x

Huang R, Pei X, Fan X, Zhang W, Li S, Li B (2012) The characteristics and failure mechanism of the largest landslide triggered by the Wenchuan earthquake, May 12, 2008, China Landslides 9:131-142 doi:10.1007/s10346-011-0276-6

Iverson RM (1997) The physics of debris flows Reviews of Geophysics 35:245-296 doi:10.1029/97rg00426

Iverson RM, Denlinger RP (2001) Flow of variably fluidized granular masses across three-dimensional terrain 1. Coulomb mixture theory Journal of Geophysical Research-Solid Earth 106:537-552 doi:10.1029/2000jb900329

Iverson RM, Reid ME, LaHusen RG (1997) Debris-flow mobilization from landslides Annual Review of Earth and Planetary Sciences 25:85-138 doi:10.1146/annurev.earth.25.1.85

Iverson RM, Vallance JW (2001) New views of granular mass flows Geology 29:115-118 doi:10.1130/00917613(2001)029<0115:nvogmf $>2.0 . c 0 ; 2$

Keith, Beven, Peter, Germann (1982) Macropores and water flow in soils Water Resources Research

Kim MS, Onda Y, Uchida T, Kim JK, Song YS (2018) Effect of seepage on shallow landslides in consideration of changes in topography: Case study including an experimental sandy slope with artificial rainfall Catena 161:50-62 doi:10.1016/j.catena.2017.10.004

Lee ML, Ng KY, Huang YF, Li WC (2014) Rainfall-induced landslides in Hulu Kelang area, Malaysia Natural Hazards 70:353-375 doi:10.1007/s11069-013-0814-8

Li C, Zhu J, Wang B, Jiang Y, Liu X, Zeng P (2016) Critical deformation velocity of landslides in different deformation phases Chinese Journal of Rock Mechanics and Engineering 35:1407-1414

Li J, Cai Q, Sun L, Chen X (2010) Reviewing on Factors and Critical Conditions of Rill Erosion Progress in Geography 29:1319-1325

Li J, Chen N, Iqbal J, Han D (2018) Model for Dilution Process of Landslide Triggered Debris Flows -A Case in the Guanba River, Southeastern Tibetan Plateau Earth Sciences Research Journal 22:103-111 doi:10.15446/esrj.v22n2.68177

Ma D et al. (2016) Effect of mining on shear sidewall groundwater inrush hazard caused by seepage instability of the penetrated karst collapse pillar Natural Hazards 82:73-93 doi:10.1007/s11069-016-2180-9

Mishra SK, Singh VP (2003) SCS-CN Method. In: Soil conservation service curve number (SCS-CN) methodology. Springer, pp 84-146

Pegram G, Parak M (2004) A review of the regional maximum flood and rational formula using geomorphological information and observed floods Water Sa 30:377-392

Polubarinova-Kochina P (1962) Theory of Groundwater Movement (trans: de Wiest, JMR) Princeton University Press. Princeton, 
Qi S, Yan F, Wang S, Xu R (2006) Characteristics, mechanism and development tendency of deformation of Maoping landslide after commission of Geheyan reservoir on the Qingjiang River, Hubei Province, China Engineering Geology 86:37-51 doi:10.1016/j.enggeo.2006.04.004 AND EARLY WARNING-PREDICTION OF LANDSLIDES Chinese Journal of Rock Mechanics and Engineering 27:1104-1112

Schiliro L, Esposito C, Mugnozza GS (2015) Evaluation of shallow landslide-triggering scenarios through a physically based approach: an example of application in the southern Messina area (northeastern Sicily, Italy) Natural Hazards and Earth System Sciences 15:2091-2109 doi:10.5194/nhess-15-2091-2015

Singh TN, Gulati A, Dontha L, Bhardwaj V (2008) Evaluating cut slope failure by numerical analysis - a case study Natural Hazards 47:263-279 doi:10.1007/s1 1069-008-9219-5

Tavenas F, Leroueil S (1981) Creep and failure of slopes in clays Canadian Geotechnical Journal 18:106-120 doi:10.1139/t81-010

Wang X, Ye J, Li B, Zhang J, Lin F, Hao Z (2010) Spatial distributions of species in an old-growth temperate forest, northeastern China Canadian Journal of Forest Research 40:1011-1019 doi:10.1139/x10-056

Yang H, Wang X, Xiao J (2014) Influence of wetting-drying cycles on strength characteristics of Nanning expansive soils Chinese Journal of Geotechnical Engineering 36:949-954

Ye J, Hao Z, Jiang P (2004) Studies on rainfall holding process of the bryophyte and litter layer in coniferous forest of Changbai Mountain Acta Ecologica Sinica 24:2859-2862

Yue H, Liu F, Yan Z (2012) Approaches to Estimate Peak-discharges by Rainfall in Small to Medium Scale River Basins Journal of Sichuan University Engineering Science Edition 44:39-44

Zhang Y, Chen N, Liu M, Wang T, Deng M, Wu K, Khanal BR (2019) Debris flows originating from colluvium deposits in hollow regions during a heavy storm process in Taining, southeastern China Landslides 17:335-347 doi:10.1007/s10346-019-01272-x

Zhang Z, Sheng L, Yang J, Chen X-A, Kong L, Wagan B (2015) Effects of Land Use and Slope Gradient on Soil Erosion in a Red Soil Hilly Watershed of Southern China Sustainability 7:14309-14325 doi:10.3390/su71014309

Zhou D, Zhang Z, Li J, Wang X (2019) Seepage-stress coupled modeling for rainfall induced loess landslide Theoretical and Applied Mechanics Letters 9:7-13 doi:10.1016/j.taml.2019.02.006 


\section{Figures}

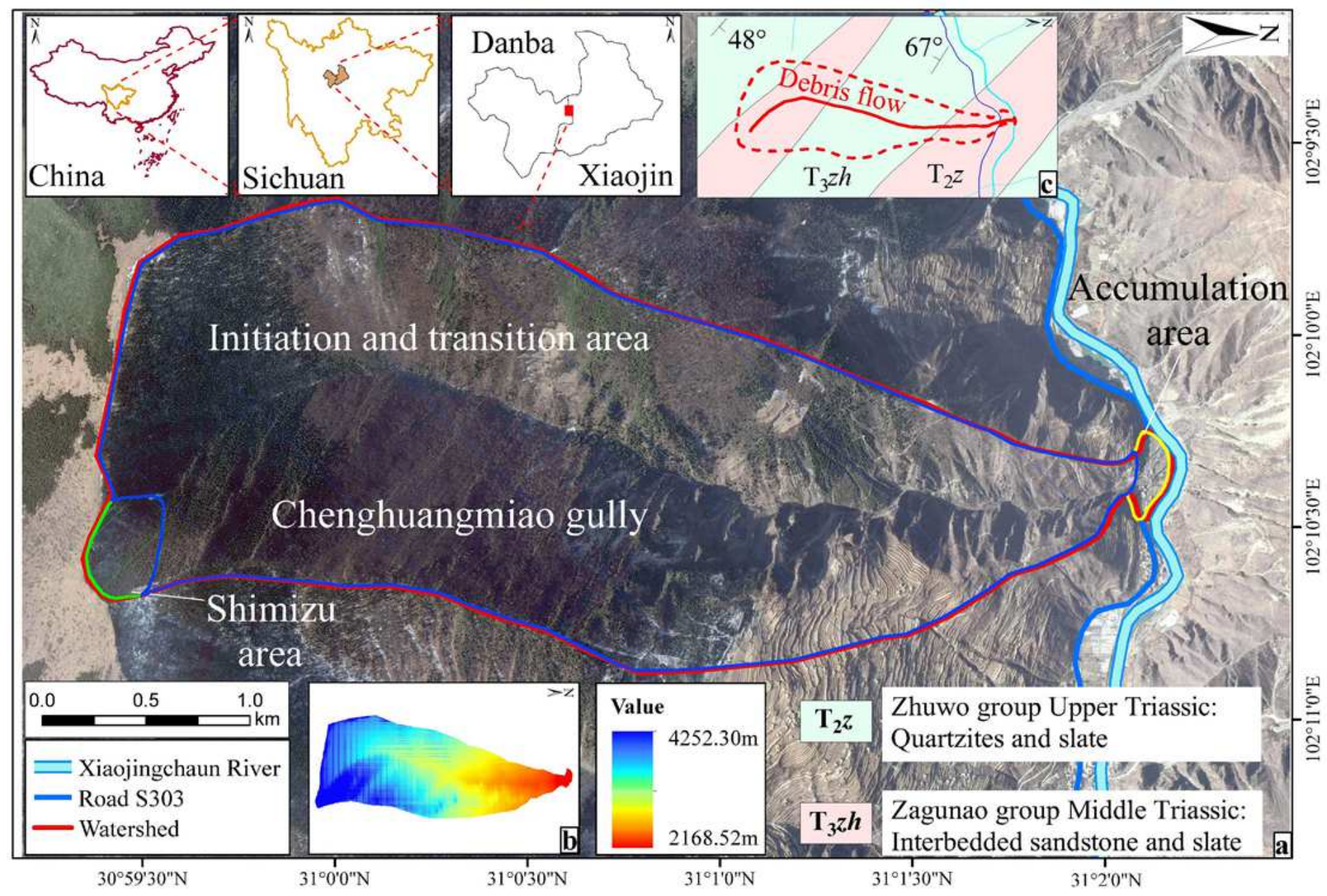

\section{Figure 1}

Chenghuangmiao Gully: (a) watershed; (b) altitude; (c) geological map. Note: The designations employed and the presentation of the material on this map do not imply the expression of any opinion whatsoever on the part of Research Square concerning the legal status of any country, territory, city or area or of its authorities, or concerning the delimitation of its frontiers or boundaries. This map has been provided by the authors. 

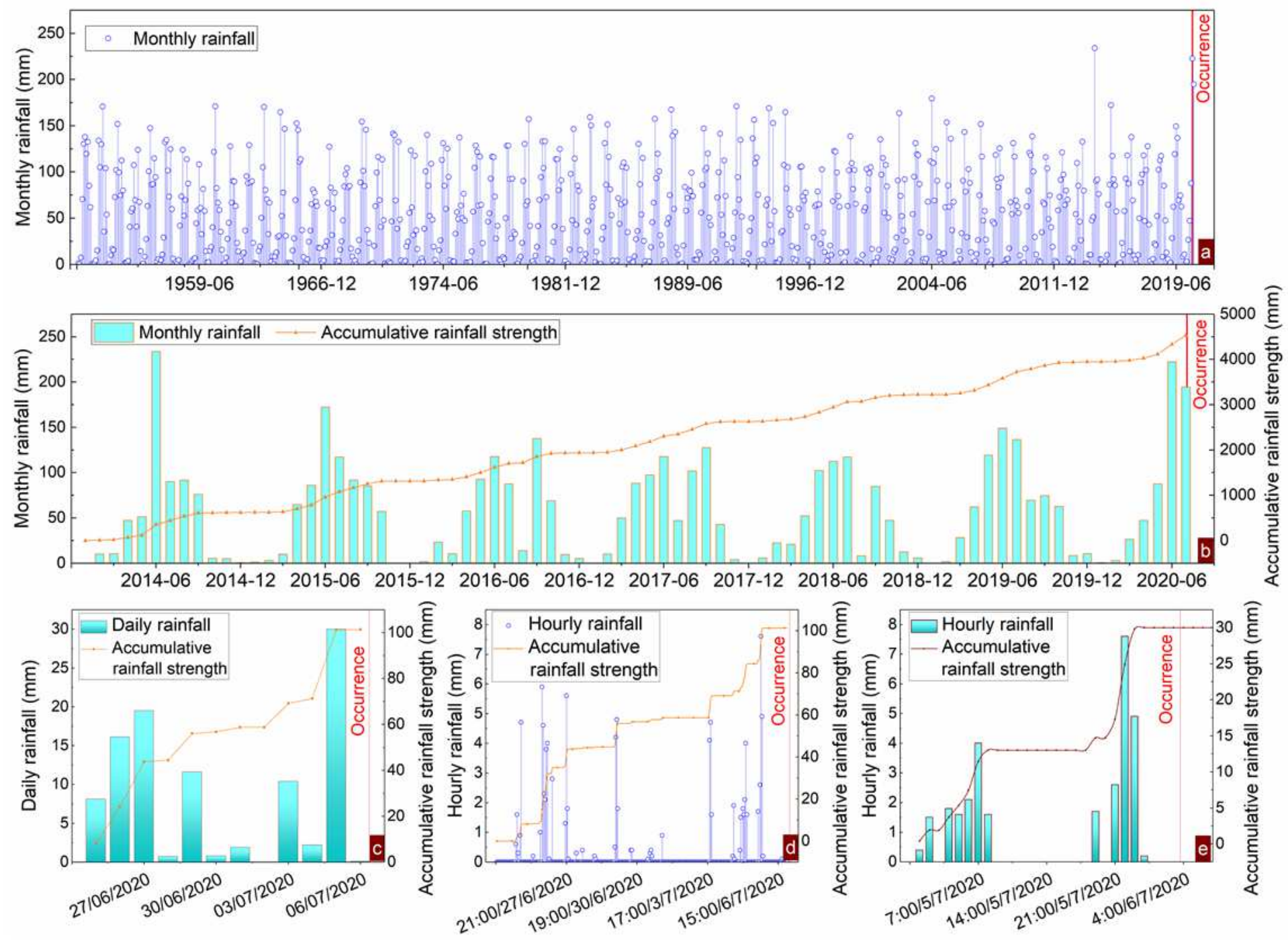

\section{Figure 2}

Rainfall trends in the study area: (a) Monthly rainfall from 1952; (b) Monthly rainfall from 2014 to 2020 ; (c) Daily rainfall in the 12 days before the occurrence of debris flow; (d) Hourly rainfall in the 12 days before the occurrence; (f) Hourly rainfall $30 \mathrm{~h}$ before the occurrence. 


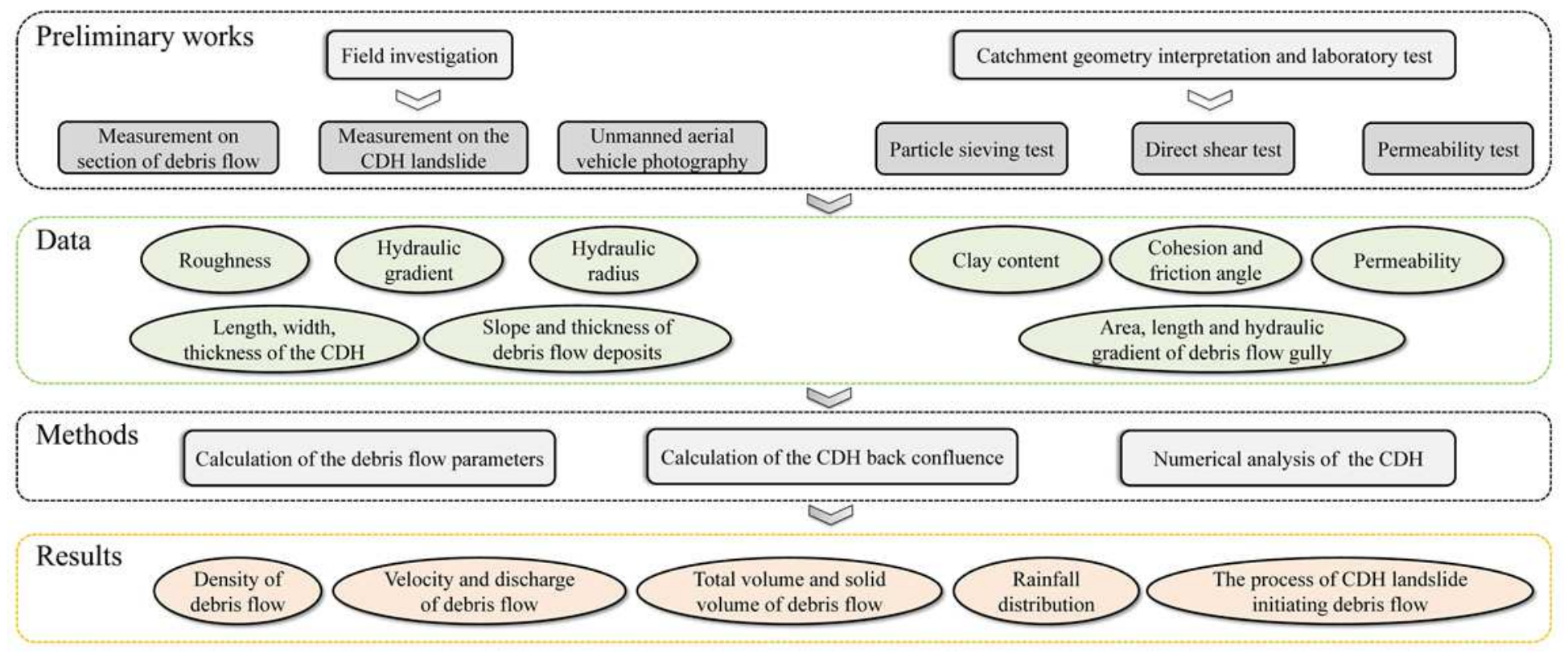

\section{Figure 3}

Methodology used to analyse the initiation of debris flow.

\section{AA` section of Chenghuangmiao debris flow}

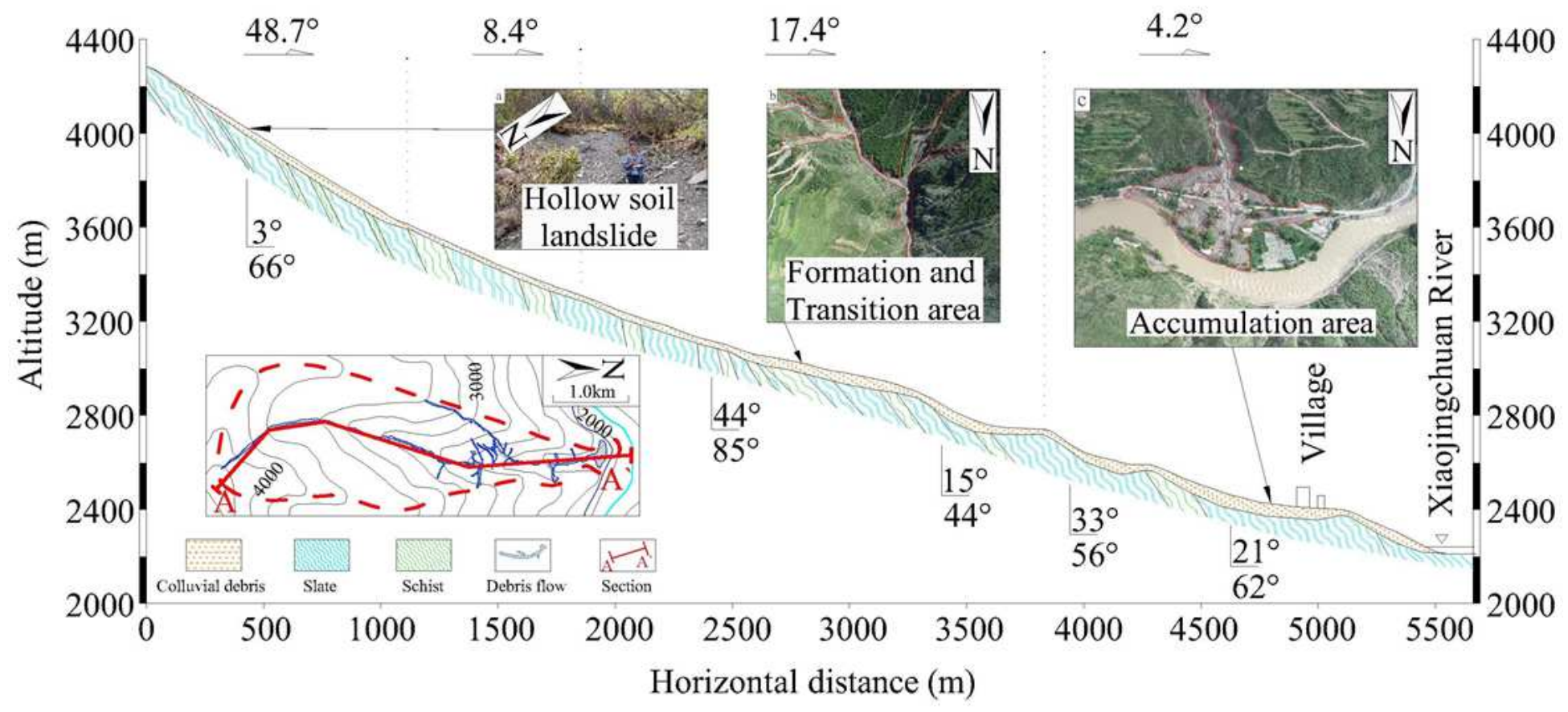

Figure 4

Plan and longitudinal section of the Chenghuangmiao Gully: (a) $\mathrm{CDH}$ landslide at the source of the Chenghuangmiao Gully; (b) Transition area; (c) Accumulation area. 


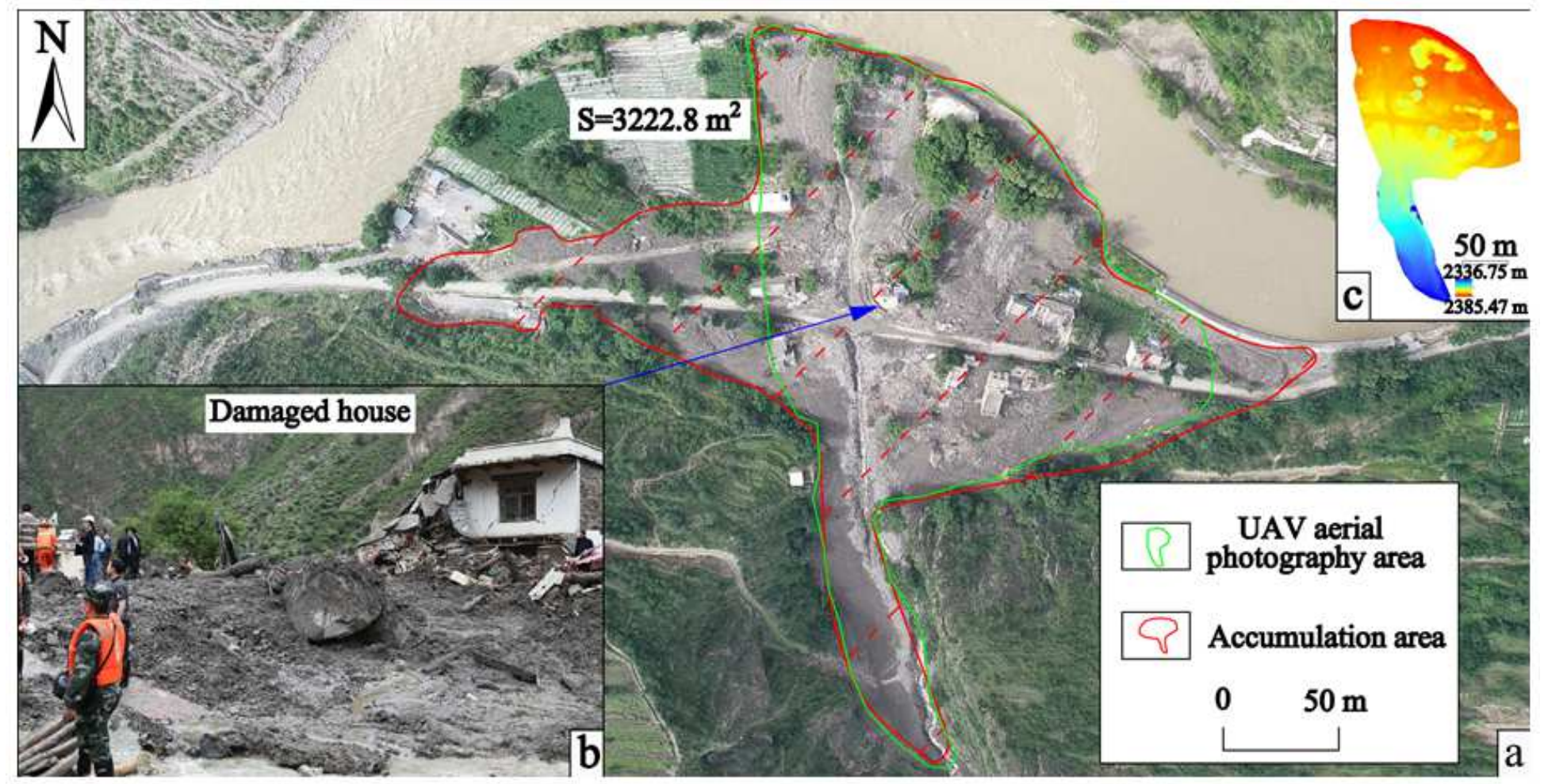

Figure 5

Accumulation area: (a) Accumulation area; (b) Washed-out houses; (c) Altitude image.

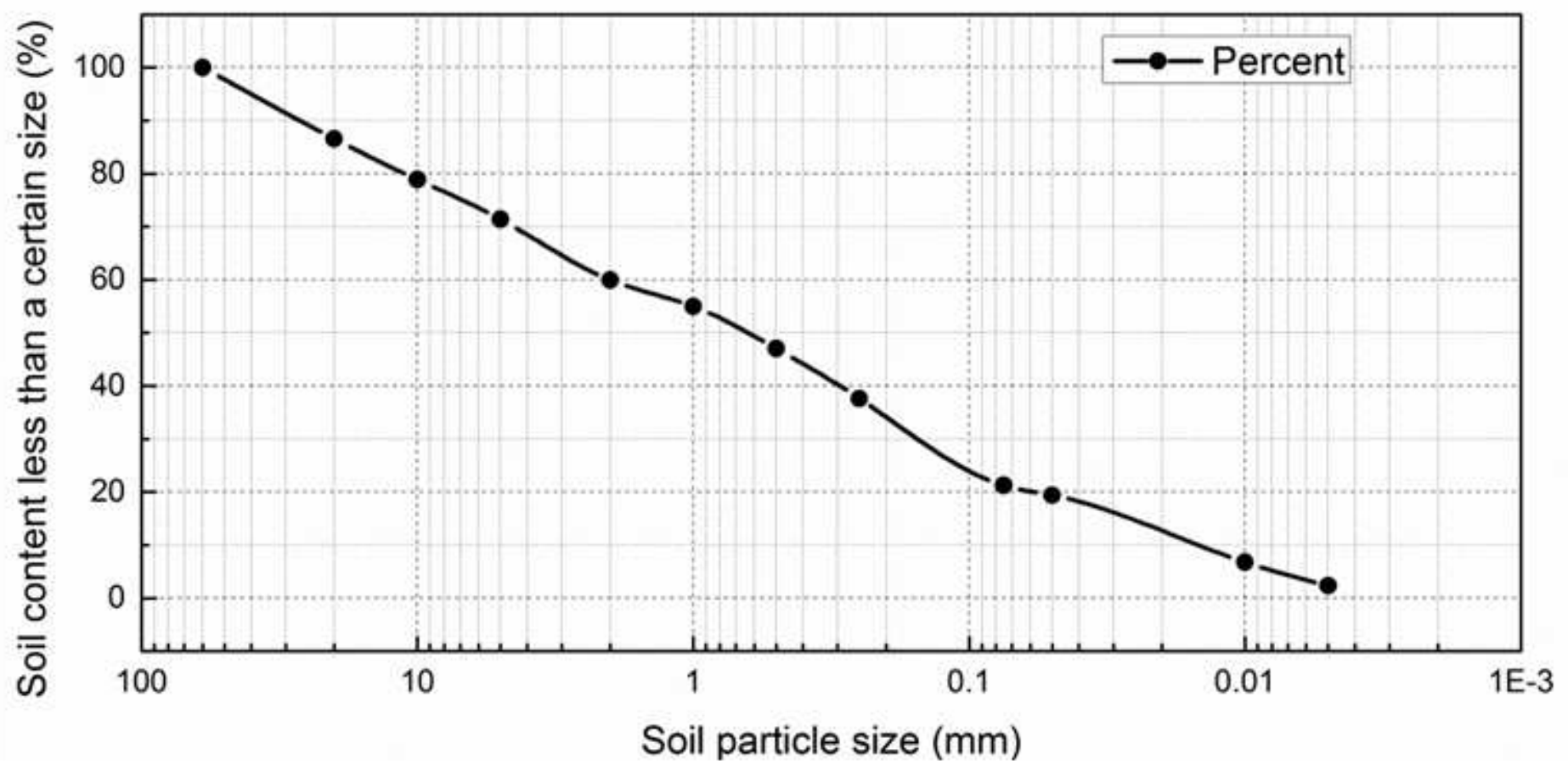

Figure 6

Debris flow accumulation particle curve. 


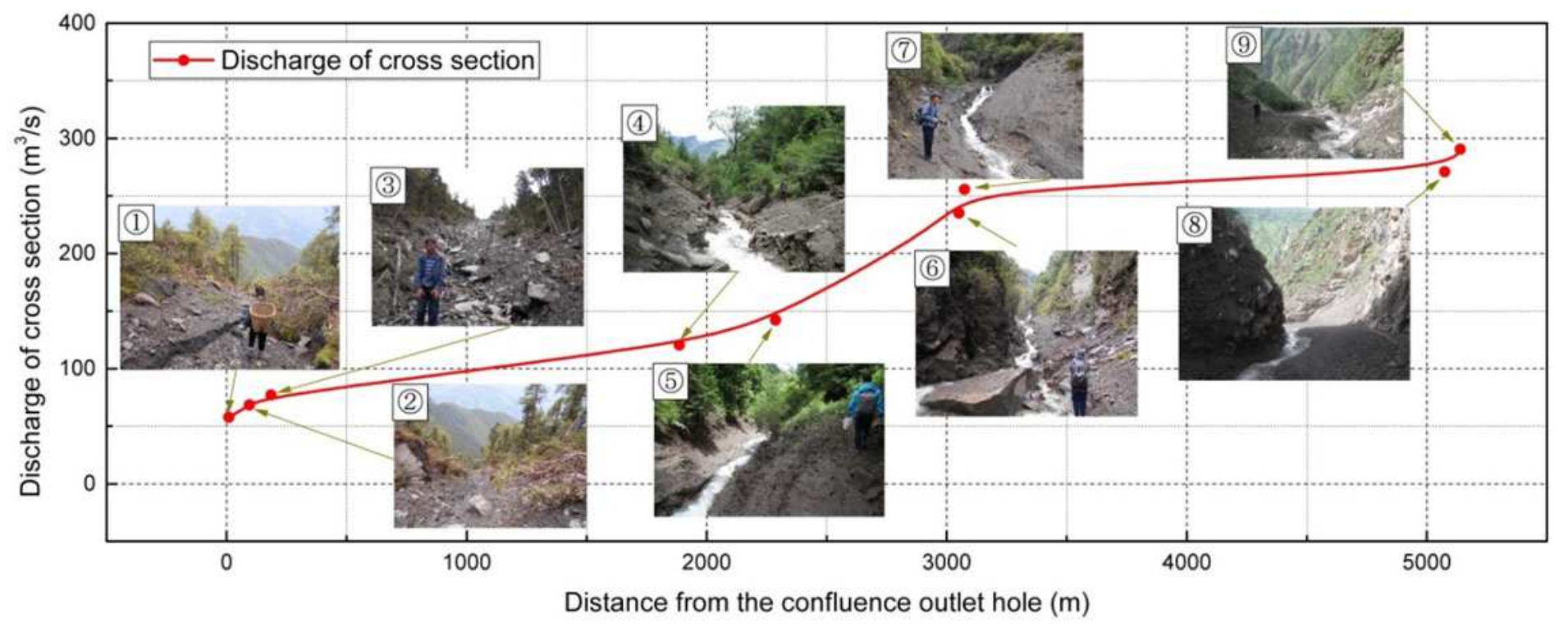

Figure 7

Debris flow discharge process.

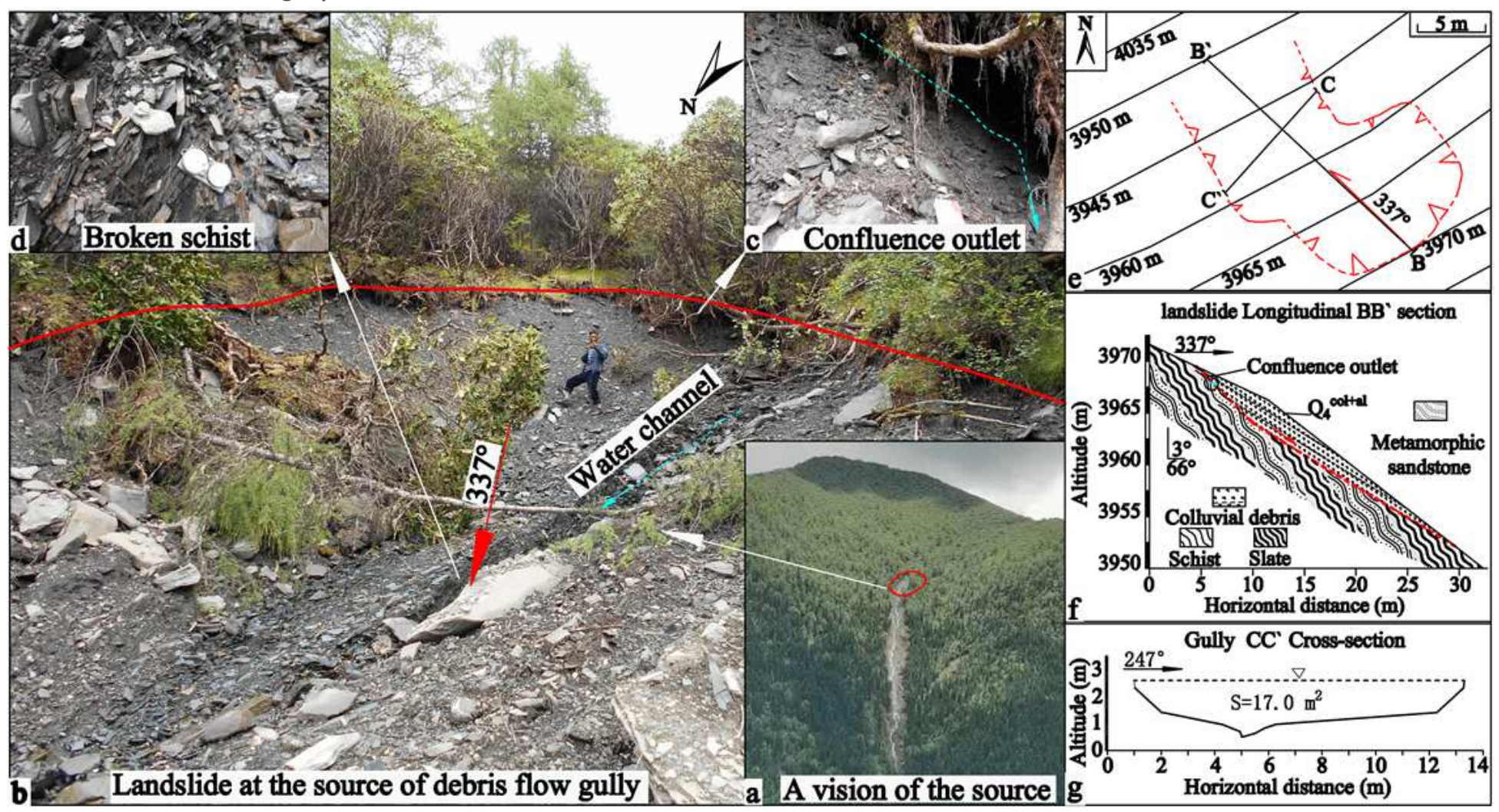

Figure 8

The CDH landslide at the source of the debris-flow gully; (a) The location of the CDH landslide at the source of the gully; (b) The trailing edge of the CDH landslide at the source of the gully and the slide bed; (c) The bedrock on the slide bed; (d) The confluence outlet; (e) Landslide plan; (f) Landslide profile; (g) Landslide cross-section. 


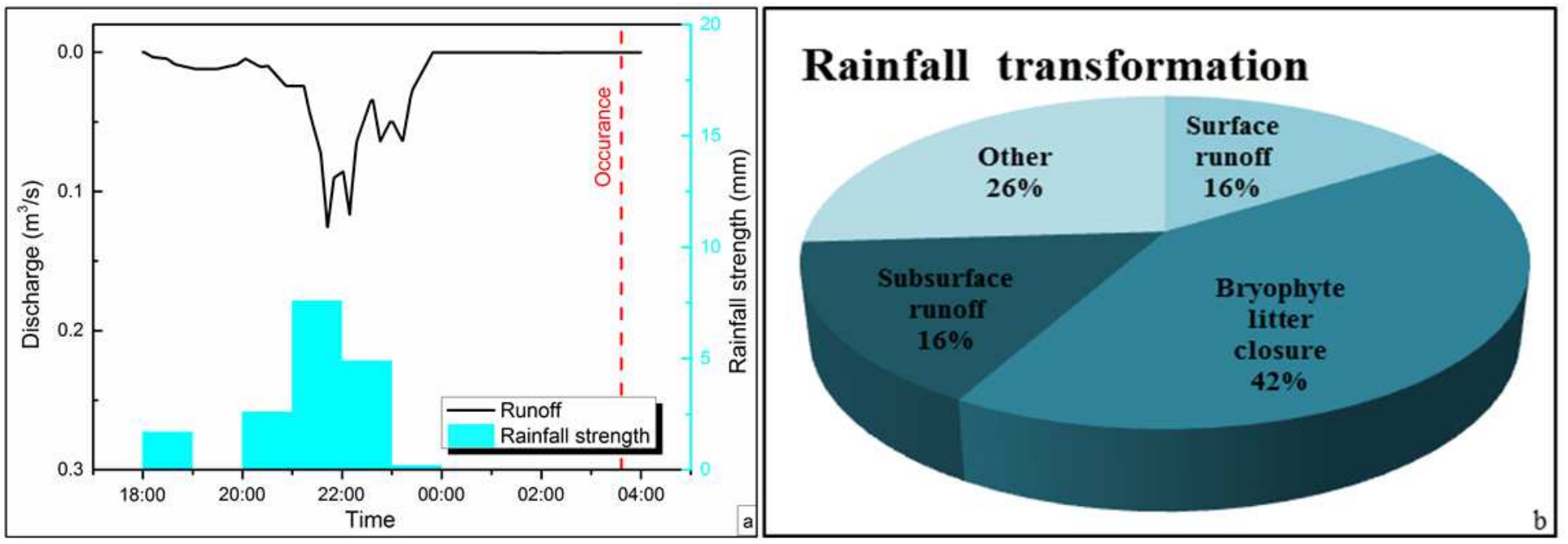

Figure 9

Rainfall and runoff: (a) Runoff process line at the back end of the $\mathrm{CDH}$; (b) Rainfall transformation pie chart.

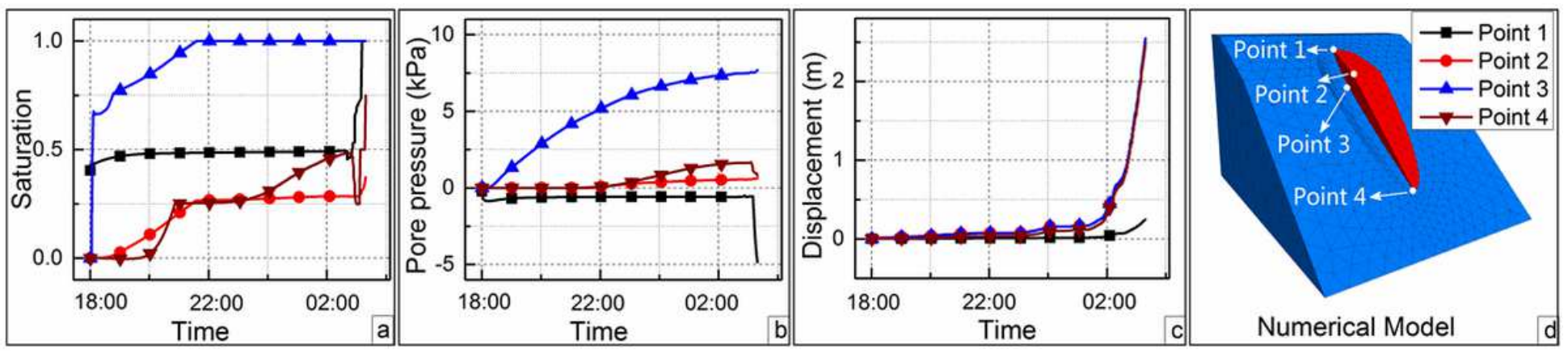

Figure 10

Variation of the $\mathrm{CDH}$ parameters at different locations with time: (a) Soil saturation variation curve; (b) Pore water pressure variation curve; (c) Deformation displacement variation curve; (d) Numerical model. 


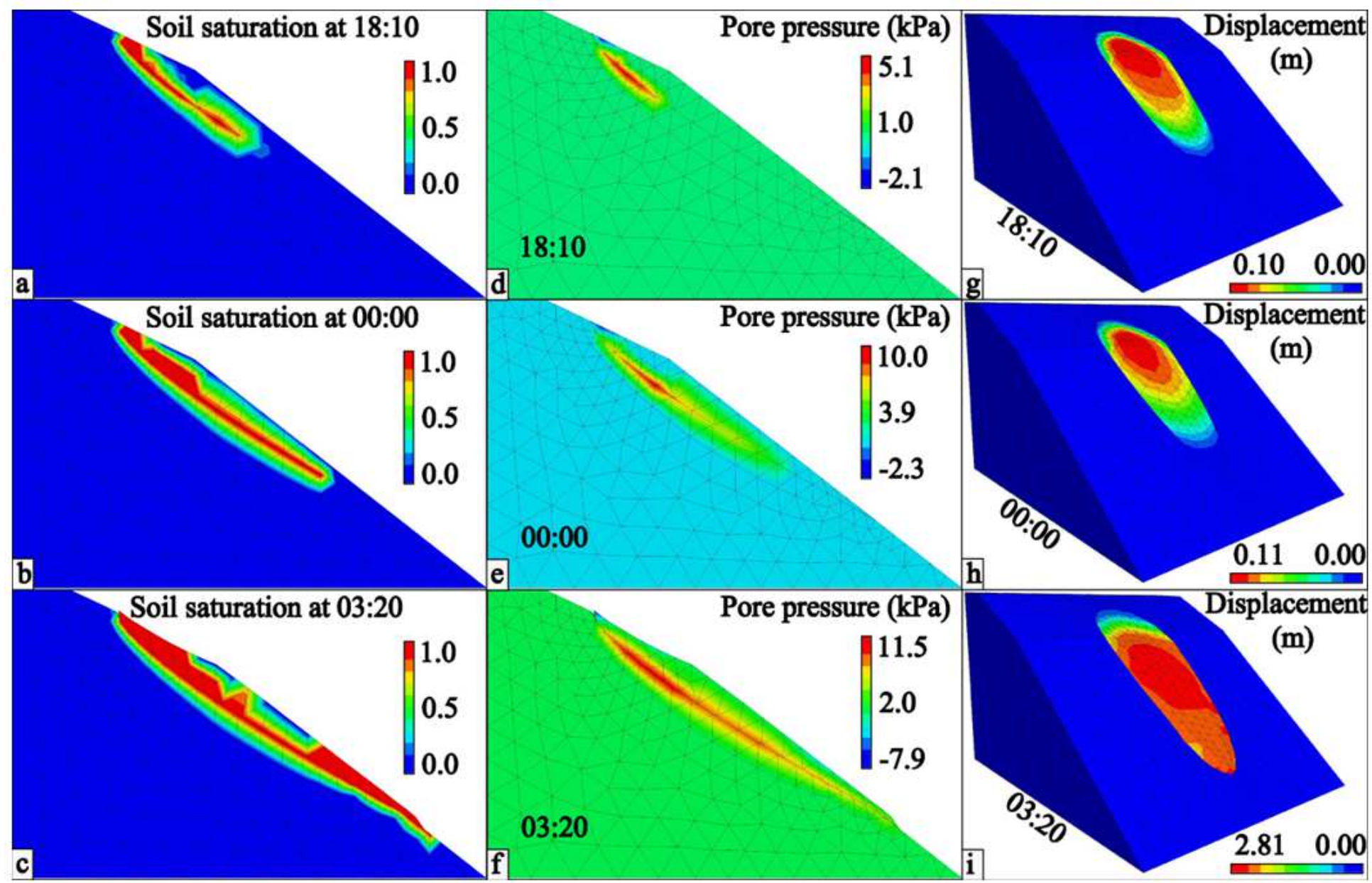

Figure 11

The CDH landslide simulation results: (a) Soil saturation at 18:10 h; (b) Soil saturation at 00:00 h; (c) Soil saturation at 03:20 h; (d) Pore water pressure distribution at 18:10 h; (e) Pore pressure distribution at 00:00 h; (f) Pore pressure distribution at 03:20 h; (g) Total soil deformation at 18:10 h; (h) Total soil deformation at 00:00 h; (i) Total soil deformation at 03:20 h.

\section{Supplementary Files}

This is a list of supplementary files associated with this preprint. Click to download.

- supplyvideo.rar 